\title{
Marked uses of tense/aspect morphology and situation type
}

\author{
Annerieke Boland \\ Linguistics/ACLC, Universiteit van Amsterdam \\ a.boland@uva.nl
}

\begin{abstract}
In this study explanations are sought for the often reported associations in child language between tense/aspect morphology and situation type. The study is done on the basis of adultadult data, child language and input language to the children. First of all it is shown that the associations are natural, since they are strong in adult-adult English as well. Only in the early stages does child language differ from this distribution, in that the associations are either stronger or different. Input data appear to account to a large extent for these differing patterns. An additional explanation is found in the discourse topics: within the context of talking about the here-and-now, the combinations of morphology and situation type that can be seen as unmarked suffice. In the context of talking about past events and of giving general comments about the world, marked combinations are necessary. It is shown that children in and their parents at the early ages mainly talk about the here-and-now, whereas adults among themselves hardly ever do so. Later, describing past events and commenting on the world becomes more frequent in child language and input, and, as a consequence, marked combinations of tense/aspect morphology and situation types increase in use.
\end{abstract}

\section{$1 \quad$ Introduction}

There are strong associations in child language between tense and aspect morphology on the one hand and situation type ${ }^{1}$ on the other hand. The following associations are reported for different languages:

- Imperfective or Progressive and activity [+dynamic, -telic] verbs

- Perfective or Past and [+dynamic, + telic] verbs ${ }^{2}$

- Imperfective or Present and state [-dynamic] verbs

Associations in first language acquisition between tense/aspect morphology and situation type appear to hold across languages, e.g. in Mandarin (Erbaugh 1978), Turkish (Aksu 1978), Japanese (Shirai 1998), Greek (Stephany 1981, 1997) and English (Shirai \& Andersen 1995), but they are not as strong in every language. The associations have also been shown to hold in the input (e.g. AksurKoç 1998, Stephany 1981, Andersen \& Shirai 1996). The distribution in adult-adult interaction however is in most studies not examined.

Various explanations have been proposed for the correlations found in child language, for example that the grammatical markers encode situation type rather than grammatical aspect or tense (e.g. Bloom, Lifter and Hafitz 1980, Bronckart and Sinclair 1973, Antinucci \& Miller

In the literature one can find labels as lexical aspect, Aktionsart or situation type to refer to the internal structure of a situation. In this article I will use the term situation type in order to avoid confusion with the term (grammatical) aspect. I will use the term situation as the neutral term for any possible situation type.

2 Some studies report that the association holds for punctual telic verbs (e.g. Shirai \& Anderson 1995), while others report an association with telic verbs in general (e.g. Tomasello 1992, Clark 1996). 
1976). This deviating use of morphemes would stem from a cognitive limitation to mark temporal deixis. Weist et al. (1984) have labeled this claim the Defective Tense Hypothesis.

Another explanation is the Prototype Account (Shirai 1991, 1994, Shirai \& Andersen 1995, Li \& Shirai 2000). On the basis of distributional analysis, children create semantic representations of tense/aspect morphology that are restricted to the prototypical situation type of the morphological category. The semantic representation excludes the combination of morphology with non-prototypical members.

The above explanations are studied in the light of data from adult-adult interaction, child language and input. The linguistic contexts in which the associations do and do not occur will be analyzed in order to explore the influence of discourse topic. An alternative explanation, the Discourse Topic Hypothesis will be presented in section 5. This approach includes the cognitive and communicative development of children and can account for the patterns found in adult-adult language, input and child language

\section{$2 \quad$ Study I: Distribution in adult-adult language}

In most studies on the acquisition of aspect, there are no data presented on the association between tense/aspect morphology and situation type of that specific language in adult-adult conversation (an exception is Stephany's study on Greek (1981) who found close similarities between patterns in adults and children). It is however necessary to know how 'natural' the association is between tense/aspect encoding and situation type, to make sure that the association is specific for child language, in other words that there is indeed a phenomenon to explain. The first question to be addressed here is: What is the distribution of tense/aspect morphology and situation type in adult English?

\subsection{Data}

This study used data from the Santa Barbara Corpus of Spoken American English (DuBois 2000). The data consist of transcribed spontaneous conversations of eight speakers: four male and four female native monolingual speakers of American English, between the ages of 19 and 50. The total sample consists of 2895 utterances. The selected files were recorded in the private home environment (except one, which was recorded in the office where the speaker works) and all consist of face-to-face conversation between two or more (maximum 5) acquainted adults.

\subsection{Coding}

All finite verbs with Simple Present, Progressive or Simple Past (regular and irregular) inflection were coded for form and situation type. The coding of situation types in this study is restricted to the oppositions between [-dynamic] and [+dynamic] situations and then, within the category of [+dynamic] situations, between [-telic] and [+telic] situations. The term state is used for all [dynamic] situations. The term activity is used for all [+dynamic/-telic] situations, thus including the category of semelfactives that Smith (1991) introduced ${ }^{3}$. Finally, the term telic situation is used for all telic situations, including both the accomplishments and achievements of Vendler's verb classification (1967). Consider Table 1:

3 Semelfactives are activities that consist of an iteration of punctual events, like cough or knock 


\begin{tabular}{|l|l|l|}
\hline STATE & \multicolumn{2}{|l|}{ - dynamic } \\
\hline ACTIVITY & \multirow{2}{*}{ + dynamic } & - telic \\
TELIC SITUATIONS & & + telic \\
\hline
\end{tabular}

Table 1: Classification of situation types

Since the internal structure of a situation does not depend on the verb alone (Verkuyl 1972), the analysis of situation types is based on the situation described by the bare verb (without tense and aspect marking), its arguments and adjuncts. Note that the classification of situations is a classification of the inherent semantics of a verb and its arguments and not a classification of "real" situations. Real situations can be viewed in various ways, even within one language: John was very scared of the dog or The dog scared John enormously both express that John was very much afraid of the dog (Dik 1997:125), but in the first example this is described by a state and in the second example by a telic situation. It is a language specific characteristic in what way linguistic forms are mapped onto the real world and it is dependent on the speaker how he chooses to describe a real world situation with the available means.

A situation is classified as a state, when it is static and stable, when it lacks 'shifts in variation' and 'consist of an undifferentiated period' (Smith 1991:37). Moreover, the criterion of input of energy is used:

With a state, unless something happens to change that state, then the state will continue (...). With a dynamic situation, on the other hand, the situation will only continue if it is continually subject to a new input of energy (...). (Comrie 1976:49)

Although there is considerable agreement in the literature on the definitions of states and nonstates, no linguistic test is available that unequivocally distinguishes states from non-states. Clear examples of activities are run in the park, take pictures, cry, and read and clear examples of states are know John, feel sorry, own a house and live in Florida. The former situations have internal dynamics and require input of energy to last in time. The latter situations, in contrast, have no internal variation and do not require an input of energy to continue. Although most situations are not so difficult to classify, there are problematic situations such as wear (a sweater), hold (a basket), wait (for the train), sleep, dream, and position verbs like stand and sit, all rather common verbs in child language. For these situations it is disputable whether they have internal dynamics and whether they require an input of energy. Shirai \& Andersen (1995) in their research on English classify each verb that yields a habitual reading in the Simple Present as an activity verb, thus including position verbs. I, however, agree with Smith (1991:250) and Comrie (1976:37) that position verbs like stand, sit and lie describe a state even though they often occur in the Progressive. With Progressive marking, these verbs refer to a state that is temporary, whereas in the Simple Present they refer to a permanent state. It is however in both cases a state, and not an activity. Only when verbs refer to a particular stance - for example Mary was sitting up as straight as she could (from Smith 1991:250) - is the situation classified as an activity. Other verbs that occur in the Progressive but seem to lack any internal variation are wait, hold, live (somewhere) and wear (clothes). They are all classified as states. Two other problematic cases are sleep and dream. In this study they are both analyzed as an activity, as opposed to be asleep, or have a dream that are analyzed as states.

Dynamic situation types can be divided into atelic and telic: a telic situation involves a certain change of state, from a 'Source State' to a 'Target State' (Klein 1994). It describes 'a process 
that leads up to a well-defined terminal point, beyond which the process cannot continue.' (Comrie 1976: 45) There are several criteria to determine the telicity of a situation. If a situation is telic, one can add a specification of the duration until the endpoint is reached, such as '(with)in an hour':

(1) She ran in the park *in an hour. atelic

(2) She drank five bottles of beer in an hour. telic

Another possible criterion is the almost-test. If almost is added to the description of an atelic situation, it only implies that the activity has never started, whereas with a telic situation, it implies either that the event never started or that it was started but not finished. Compare (3) and (4):

(3) I almost sang but I didn't start/* but I didn't finish it atelic

(4) I almost sang the song but I didn't start/but I didn't finish it telic

Finally, the question: 'If $\mathrm{X}$ is interrupted in the course of VERB-ing, has she then VERB-ed?' is answered with 'yes' if the situation is atelic and with 'no' if the situation is telic, consider (5) and (6):

(5) If John is interrupted in the course of searching for a stamp, has he then searched for a stamp? Answer: Yes. atelic

(6) If John is interrupted in the course of writing a letter, has he then written a letter?

Answer: No. telic

The encoding was always based on the interpretation of the specific utterance within the discourse.

\subsection{Results}

In the adult conversations, there were in total 995 tokens of a Simple Present, Progressive or Simple Past that were all coded for situation type. The distribution of situation type over tense/aspect morphology was analyzed at first for each adult individually. The distribution presented in Figure 1 is the weighted mean of these distributions.

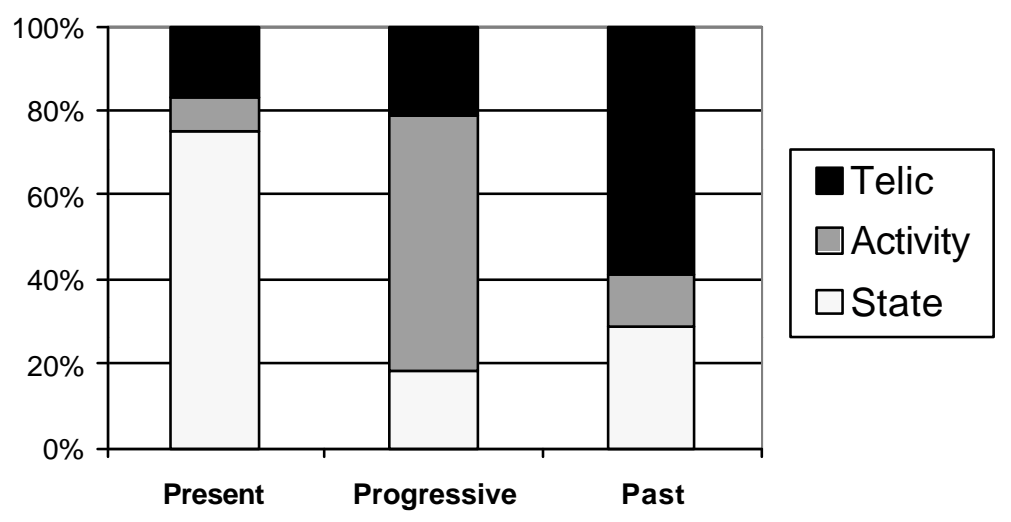

Figure 1: Proportion of situation types for Simple Present $(n=569)$, Progressive $(n=121)$, and Simple Past $(n=305)$ morphology in English adult-adult conversation. 
The conversational data of adults show a strong association between Simple Present and states (mean 75\%), between Progressive and activities (mean 60\%) and between Simple Past and telic situations (mean 59\%). Hereafter, these combinations will be referred to as 'unmarked'. Of all the Simple Present tokens only $8 \%$ combines with activities and $17 \%$ with telic situations. The Progressive combines with states in $19 \%$ of all cases and with telic situations in $21 \%$ of all cases. Of all the Past tokens $29 \%$ combines with states and $12 \%$ with activities. These combinations will be referred to as 'marked'.

\subsection{Conclusion}

There is a level of association between tense/aspect morphology and situation type that is perfectly natural in conversational English: about $60 \%$ association between Progressive and activities and Past and telic situations and $75 \%$ between Present and states. The question is whether children differ from this pattern of associations in their production. Only insofar as the associations in English child language or input are stronger or weaker than the adult-adult level or different altogether, is there a phenomenon specific for child language that needs explaining.

\section{$3 \quad$ Study II: Child language}

The second question addressed in this study is whether the association between tense/aspect morphology and situation type in child language differs from adult language. In study I it was shown that a certain level of association is standard or natural for English conversation. Only if children behave differently from this pattern, it is meaningful to investigate the factors that influence the distributional patterns in child language. Therefore, in the second study, the development in child language will be investigated.

In the literature on the acquisition of tense/aspect morphology in English (Bloom, Lifter \& Hafitz 1980, Clark 1996, Shirai 1991, Shirai \& Andersen 1995, Tomasello 1992) there is agreement that the Progressive is overwhelmingly used with activities and the Past with telic situations, figures running up to 90 or $100 \%$. The study of the Simple Present is restricted to the acquisition of third person singular $-s$ and here the results are not very consistent or not reported at all. These studies suggest that there is indeed a difference between adults and children, but since analyses differ from study to study, the reports from the literature cannot be compared to the adult data of study I. Child language has to be coded in the same way as the adult data in order to be able to compare the results.

\subsection{Data}

The transcribed spontaneous speech of three monolingual American English children was used from CHILDES (MacWhinney \& Snow 1985, 1990, MacWhinney 1995). The first child, Naomi, was studied at 1;6, 1;9, 2;0, 2;3, 2;6 and 3;0 (Sachs 1983); the second child, Nina, was studied at 2;0, 2;3, 2;6 and 3;0 (Suppes 1973); and the third child, Abe, was studied at 2;6, $3 ; 0,3 ; 6,4 ; 0,4 ; 6,5 ; 0$ (Kuczaj 1977). Each sample consisted of the first 750 child utterances that were available of that particular age. If there were not enough utterances available of the specific month, then utterances of the preceding or following month were used.

\subsection{Coding}

The data were encoded in the same way as the adult conversations (see section 2.2). Every adult-like combination of a Subject and a Present form, such as I want, he has, it looks like ... 
etcetera, was encoded as Simple Present. For the Progressive and the Simple Past, only the inflection (not the presence of a Subject) was taken as a criterion for inclusion.

The chi-squared test was applied in order to find out whether the distribution in the child samples is significantly different from the adult sample. The significance level was set at $\alpha=$ 0.05 . Whenever the chi-squared test could not be applied because the expected value in one of the cells was lower than 5, the two categories that form a marked combination with the morphology were combined for the analysis: this is always described in the text.

\subsection{Results}

\subsubsection{Progressive}

Figures 2-4 display the proportion of situation types in the Progressive. The rightmost column presents the distribution in the adult conversations, which was also presented in Figure 1.

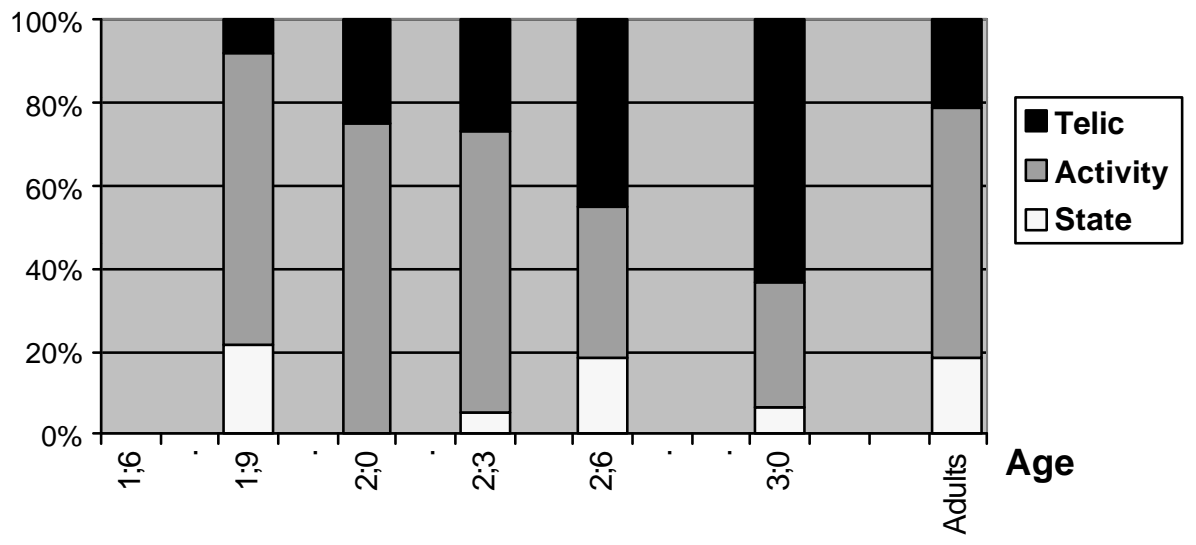

Figure 2: Naomi's use of Progressive compared to adult sample: proportion of situation types.

Naomi's distribution of situation types in the Progressive (Figure 2) is at $1 ; 9$ and $2 ; 3$ not different from what adults do. At 2;0, the marked combinations (states and telic situations) had to be added up in order to apply the chi-squared test. Although this yielded a nonsignificant difference, it is remarkable that there are no states in Naomi's data. The samples at ages 2;6 and 3;0 are significantly different from the adult sample, mainly due to a far greater proportion of telic situations in the Progressive.

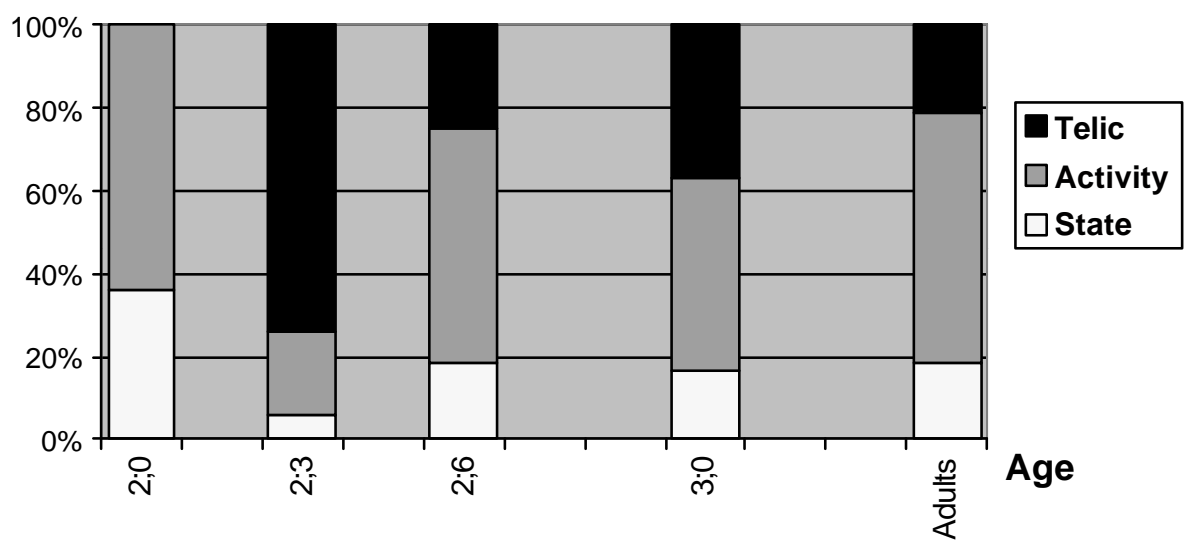

Figure 3: Nina's use of Progressive compared to adult sample: proportion of situation types

The results for Nina are presented in Figure 3. At age 2;0 the marked combinations (with states and telic situations) had to be combined for applying the chi-squared test: there was no 
significant difference with the adults $\left(X^{2}=0,81\right.$ n.s. $)$. It is however remarkable that Nina does not use the Progressive with telic situations at all.

Nina at $2 ; 3$ is significantly different from the adult sample $\left(X^{2}=3,41.10^{-8}\right)$ in that her proportion of telic situations is larger and of activities and states smaller. At 2;6 the chisquared test could only be applied when states and telic situations were taken as one category. Then, there was no significant difference $\left(X^{2}=0,77\right.$ n.s. $)$ with the adult-adult distribution. At 3;0 there was no significant difference either $\left(X^{2}=0,20\right.$ n.s. $)$.

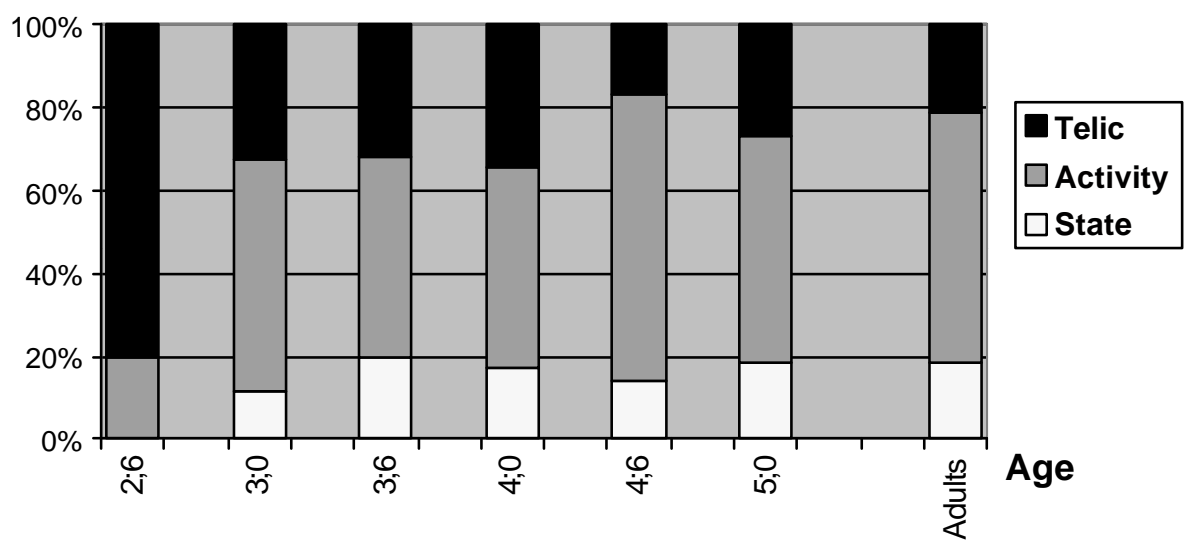

Figure 4: Abe's use of Progressive compared to adult sample: proportion of situation types.

The results for Abe are presented in Figure 4. At 2;6 the unmarked categories had to be combined which yielded a significant difference from what adults do $\left(X^{2}=0,000262\right)$ : the proportion of telic situations is larger and there are fewer states (none at all) and activities. From age 3;0 the proportions of situation types in Abe's Progressives are similar to adults.

To summarize, contrary to findings in the literature, these data show that the association between activities and the Progressive in child language is never stronger than in adult language. Where children, however, do differ from adult language is that there is at least one sample for each child in which the proportion of telic situations is the largest. Furthermore, the samples Naomi at 2;0, Nina at 2;3 and Abe at 2;6 contain no or hardly any states and the language of Nina at 2;0 does not contain a single telic situation.

\subsubsection{Simple Past}

In Figure 5-7 the proportion of situation types in the Past are presented. The column on the right presents the distribution in the adults' conversations, already presented in Figure 1.

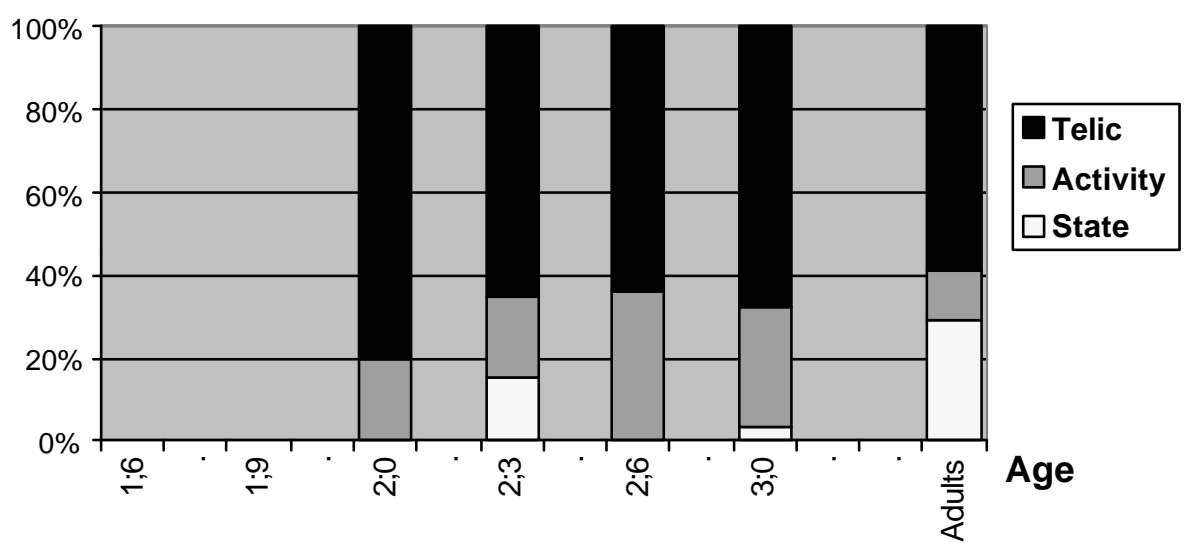

Figure 5: Naomi's use of Simple Past compared to adult sample: proportion of situation types. 
Naomi's use of the Simple Past is presented in Figure 5. At 2;0 the chi-squared test could not be used at all, but the proportion of telic situations is large $(80 \%, n=10)$. For all the other samples the test could only be applied when the marked situation types (states and activities) were taken as one category. Contrary to expectations based on the literature, there were no significant differences found: the association between Past tense and telic situations was as strong as in the adult sample. However, within the group of marked combinations, the proportion of states of Naomi's Past Tense forms is always low and consequently, the proportion of activities is high.

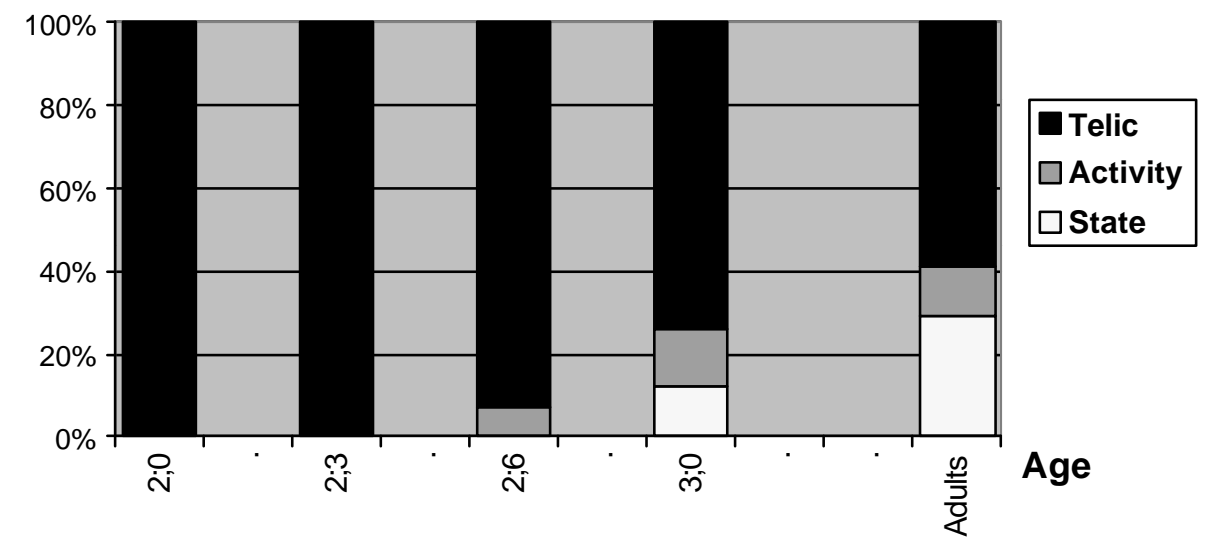

Figure 6: Nina's use of Simple Past compared to adult sample: proportion of situation types.

Nina's use of the Past is presented in Figure 6. At age 2;0 and 2;3 the chi-squared test could not be used, since there were no states and activities at all. The association between Past and telic situations is here thus $100 \%$, which is in accordance with results reported in the literature. It should be noted, however, that at $2 ; 0$, the only past forms that Nina used was eleven times gave; at 2;3 Nina uses only two tokens: mashed (1x) en fell down (1x). This suggests that the Past Tense is by no means productive at these ages. At 2;6, states and activities had to be combined in order to apply the chi-squared test. This yields a significant difference $\left(X^{2}=0,01057\right)$ : the proportion of telic situations in Nina's language is larger than in the adult sample. At age 3;0 there is no longer a significant difference.

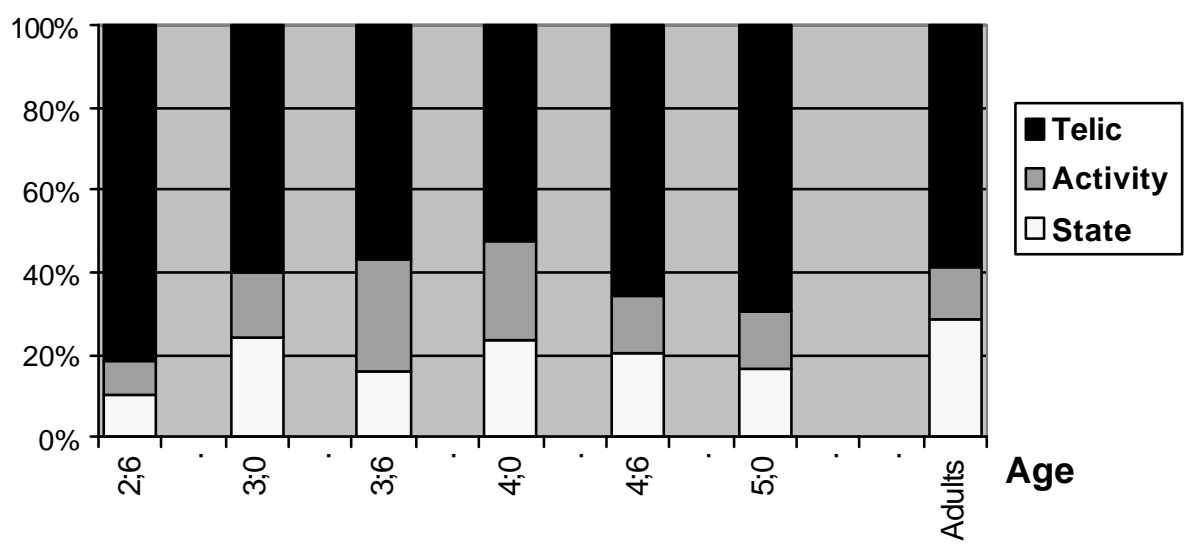

Figure 7: Abe's use of Simple Past compared to adult sample: proportion of situation types.

Abe's use of the Past is presented in Figure 7. At 2;6 the proportion of states is smaller and of telic situations larger than in the adult sample $\left(X^{2}=0,007\right)$, which is in accordance with the literature. At 3;0 there is no significant difference. At 3;6 the proportion of activities is larger and of telic situations smaller than in the adult sample $\left(X^{2}=0,000182\right)$ and also at $4 ; 0$, the proportion of activities is larger than in the adult sample $\left(X^{2}=0,009535\right)$. This was not 
expected on the basis of the literature. At 4;6 and 5;0 there are no differences between Abe and the adult sample.

In summary, the data show that the associations between Past tense and telic situations is not specific for child language, but the association in child language seems to be stronger for all children up to age 2;6. This confirms earlier findings. Note, however, that the number of tokens and types is small which suggests that the inflection is not yet productively used. Finally, there are a few samples (Abe at 3;6 and 4;0 and the samples of Naomi) in which the proportion of activities is remarkably large. In all child samples the proportion of states is smaller than in the adult sample.

\subsubsection{Simple Present}

In Figures 8-10 the proportions of situation type for the Simple Present are presented. The column on the right presents the distribution in the adult sample (as presented in Figure 1).

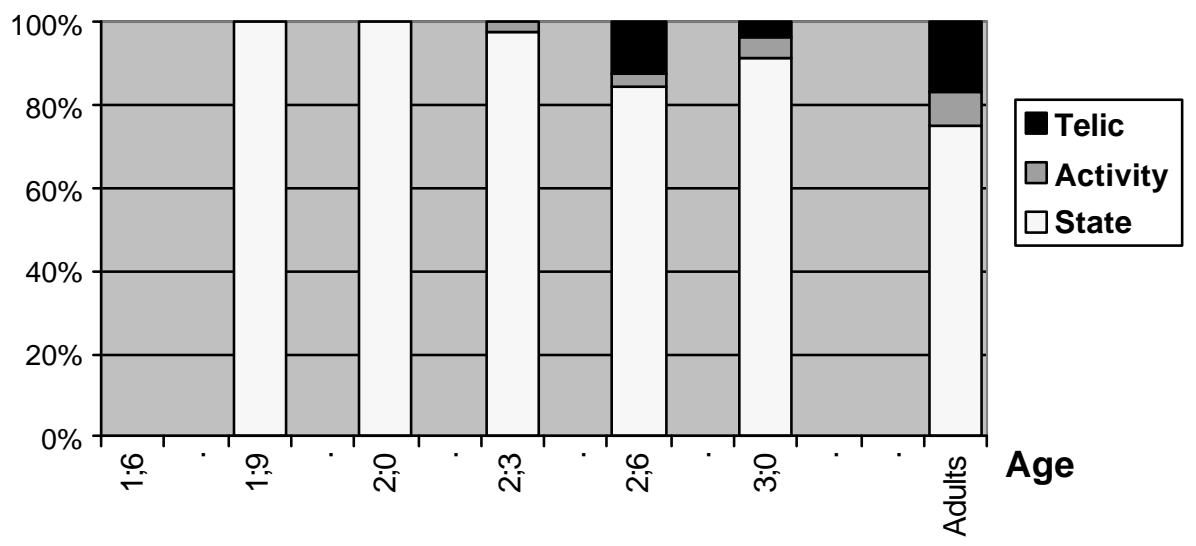

Figure 8: Naomi's use of Simple Present compared to adult sample: proportion of situation types.

For Naomi's data at 1;9 and 2;0 (Figure 8) the chi-squared test could not be applied, since there are no activities and telic situations at all. At 2;3, when marked situation types are combined, the difference is significant $\left(X^{2}=0,000207\right)$ : the proportion of states is larger than in the adult sample. At 2;6 there is no significant difference. At 3;0 the difference is significant $\left(\mathrm{X}^{2}=0,002414\right)$ in that Naomi's proportion of states is larger and of telic situations smaller.

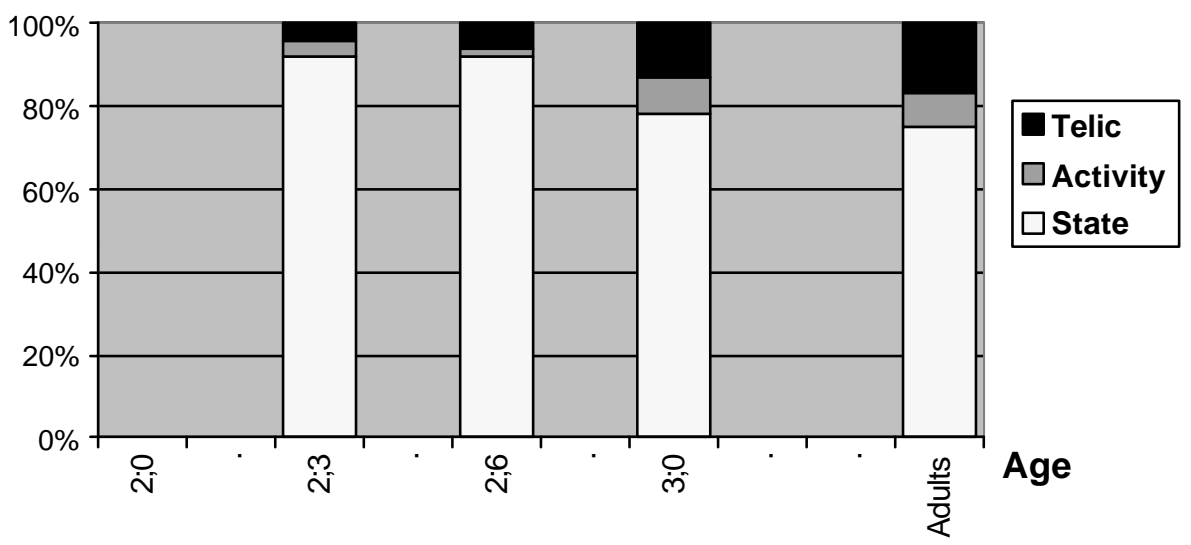

Figure 9: Nina's use of Simple Present compared to adult sample: proportion of situation types.

At age 2;0, Nina does not use a single form of the Simple Present (Figure 9). At 2;3, activities and telic situations have to be combined in order to apply the chi-squared test: there is no 
significant difference between Nina and the adult sample $\left(X^{2}=0,051143\right.$ n.s. $)$. At age $2 ; 6$ Nina's language differs significantly $\left(X^{2}=0,006606\right)$ from the adult sample in that her proportions of activities and telic situations are smaller. At 3;0, there is no significant difference.

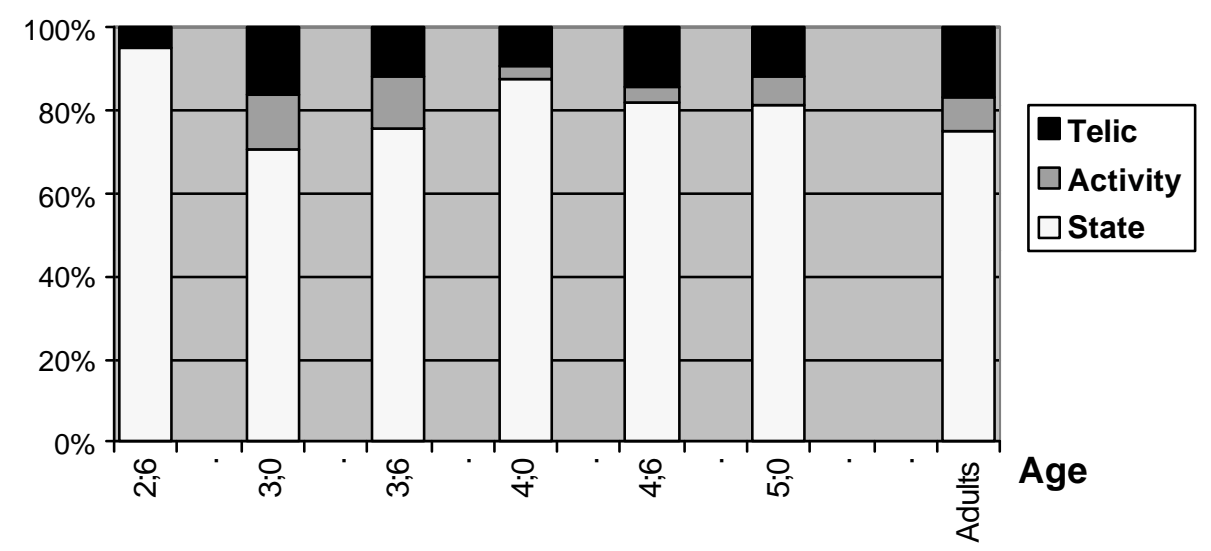

Figure 10: Abe's use of Simple Present compared to adult sample: proportion of situation types.

At 2;6, Abe's data (Figure 10) are significantly different from the adult sample $\left(\mathrm{X}^{2}=7,39.10^{-5}\right)$ : Abe's proportion of states is larger and of activities and telic situations smaller. There is also a significant difference between Abe 4;0 and the adult sample $\left(\mathrm{X}^{2}=0,00725\right)$ : once more Abe uses more states and fewer activities and telic situations than the adults. The other samples $(3 ; 0,3 ; 6,4 ; 6,5 ; 0)$ do not differ from the adults.

In summary, the data show that the association between Simple Present and states is in general stronger in early child language than in adult language. Between the ages of 2;6 and $4 ; 0$ the association gets weaker and reaches the adult level.

\subsection{Conclusion}

The results from the children's data show that there is a difference between the associations of morphology and situation types in adult and child English. Firstly, although from the earliest samples on the association between Progressive and activities is not significantly stronger than in adult-adult language, the children's usage differs on one count: in at least one sample of each child the association between the Progressive and telic situations is strongest. Furthermore the association between Progressive and states is very weak in at least one sample of each child. Secondly, the association in early child language between Past and telic situations is stronger in child language than in adult English, which is in accordance with the literature. Furthermore, the proportion of states in the Simple Past is remarkably small and the proportion of activities is sometimes larger than for adults. Thirdly, the association between Present and states is stronger in child than in adult language and only gradually weakens. The question thus arises why children differ from adults on these points: how can we explain the differences in distribution?

\section{$4 \quad$ Study III: Input}

Why do the associations between tense/aspect morphology and situation type in child language differ from adult-adult language? A possible explanation is the input. Language directed to children differs from what adults do when they converse among themselves and it might be the case that the distribution of situation types over morphology in child directed 
speech differs from adult-adult interaction. The patterns found in child language might just be a reflection of the distribution in the input. So we pose the questions: Can the input account for the different patterns in child language, more specifically: a strong association between telic situations and Progressive in a few samples, a strong association between Past and telic situations and between Present and states?

\subsection{Data}

In order to find out whether the input is different from adult-adult conversation and whether the distribution in child language and input is comparable, the input to two of the three children, Nina and Abe, is studied. The same CHILDES samples are used as for the child samples. The input to Nina is investigated at 2;0,2;6, and 3;0 and for the Progressive also at $2 ; 3$. In Nina's samples the input is only from her mother. The input to Abe is investigated at $2 ; 6,3 ; 0,3 ; 6$ and $4 ; 6$ and consists of utterances from both parents and a few utterances from his grandmother.

\subsection{Coding}

All the adult utterances addressed to the child in the specific sample are coded in the same way as the child and adult samples (see section 2.2).

\subsection{Results}

\subsubsection{Progressive}

Figures 11-12 present the results for the Progressive. The results for the child and the input in one sample are presented in columns next to each other at each age. The rightmost column displays the distribution in the adult-adult conversations.

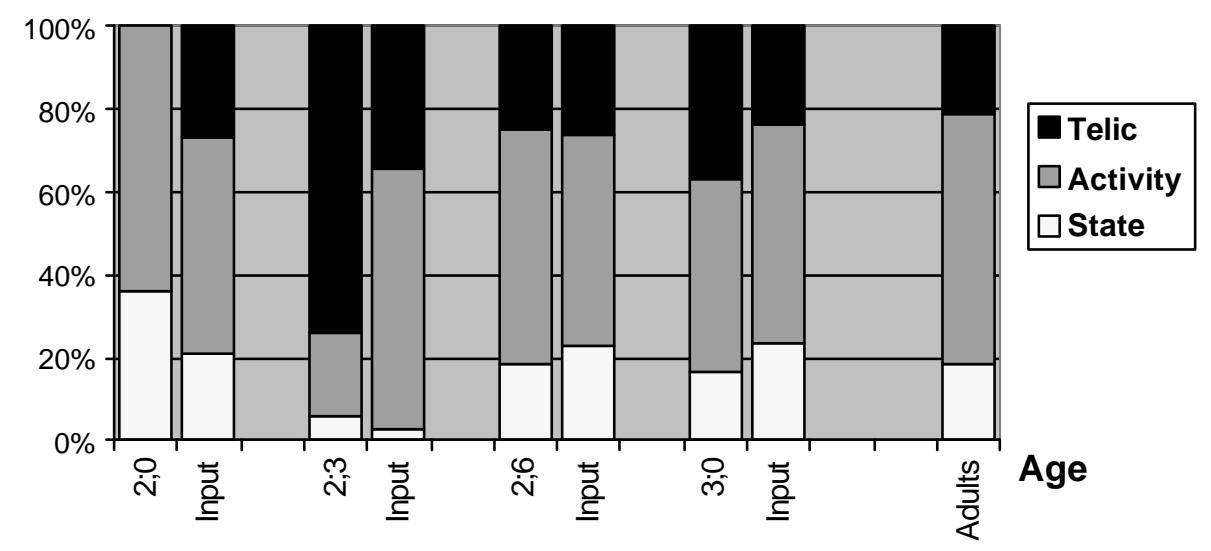

Figure 11: Input to Nina: proportion of situation types in Progressive

The input to Nina at age 2;0 is similar to the distribution in the adult sample (Figure 11). At $2 ; 3$ the input is significantly different from the adult sample $\left(X^{2}=4,394.10^{-4}\right)$ in that the proportion of telic situations is larger and of states smaller. In the other samples the input is comparable to the adult sample.

The difference between the input and Nina's language at 2;0 and at 2;3 could only be calculated when the marked combinations (states and telic situations) are added up. At 2;0 there is no significant difference, although it is remarkable that there are no telic situations at all in Nina's data. At 2;3 there is a significant difference $\left(X^{2}=1,26.10^{-5}\right)$, in that the proportion of activities in the input is larger and of telic situations smaller than in Nina's speech. This 
difference is the result of the frequent use of the mother of the question: What are you doing? and Who are you hammering? In the other samples, input and child language are comparable.

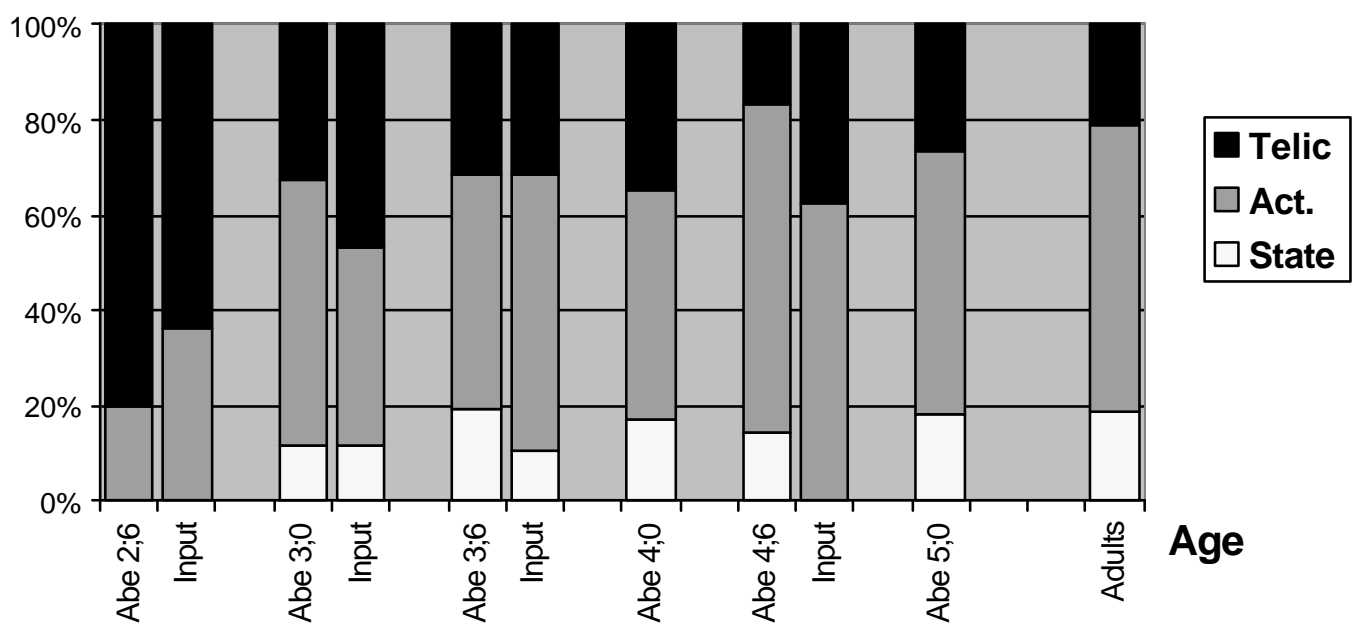

Figure 12: Input to Abe: proportion of situation types in Progressive.

The input to Abe (Figure 12) differs significantly from the adult sample $\left(X^{2}=5,806.10^{-6}\right)$ at 2;6 in that the proportion of telic situations is larger in the input than in the adult sample and there are no states at all. The input at 3;0 is also significantly different from the adult sample $\left(\mathrm{X}^{2}=0,011\right)$ because the proportion of telic situations in the input is large. There are no significant differences between Abe's language and the input.

In summary, the distribution in the input can to a large extent account for the patterns in the child samples. The input differs in similar ways from the adult-adult conversation as the child language does: the association between telic situations and the Progressive is stronger in the input than in adult-adult language and the association between states and Progressive is in a few samples weaker. The correlation between input and child language is high: for Abe there are no differences at all and for Nina only in the beginning. At 2;3 the proportion of telic situations in Nina's language is larger and of activities smaller than in the input, but this can be explained by the repeated questions of the mother. The only pattern that cannot be explained by the input is that there are no telic situations in Nina's data at 2;0, whereas they are present in the input.

\subsubsection{Simple Past}

Figures 13-14 present the results for the Simple Past.

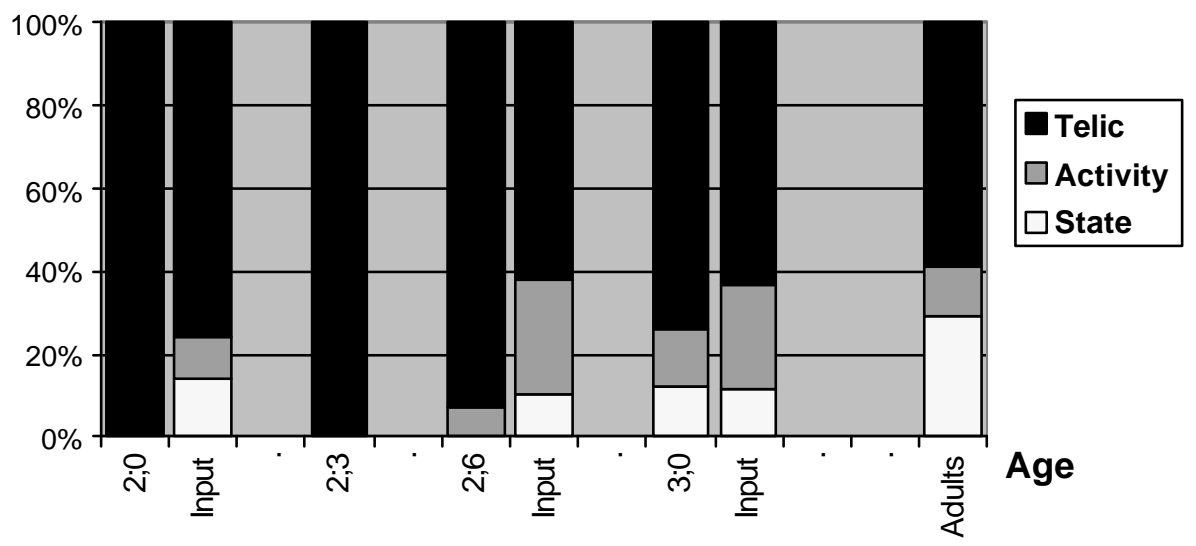

Figure 13: Input to Nina: proportion of situation types in Simple Past. 
For Nina (Figure 13) all the input samples are significantly different from the adult sample. At age 2;0 $\left(X^{2}=0,01522\right)$ the proportion of telic situations in the input is larger and of states smaller than in the adult sample. At age $2 ; 6\left(\mathrm{X}^{2}=3,85.10^{-5}\right)$ and $3 ; 0\left(\mathrm{X}^{2}=1,27.10^{-6}\right)$ the proportion of activities is larger and of states smaller than in the adult sample.

The chi-squared test could not be applied to calculate the difference between the input and Nina's language at 2;0 and 2;6: the expected values were too low. It is however remarkable that the proportion of telic situations in Nina's speech is so high, compared to the input. At $3 ; 0$, when the state and activities were combined, there appeared to be no significant difference between input and child language.

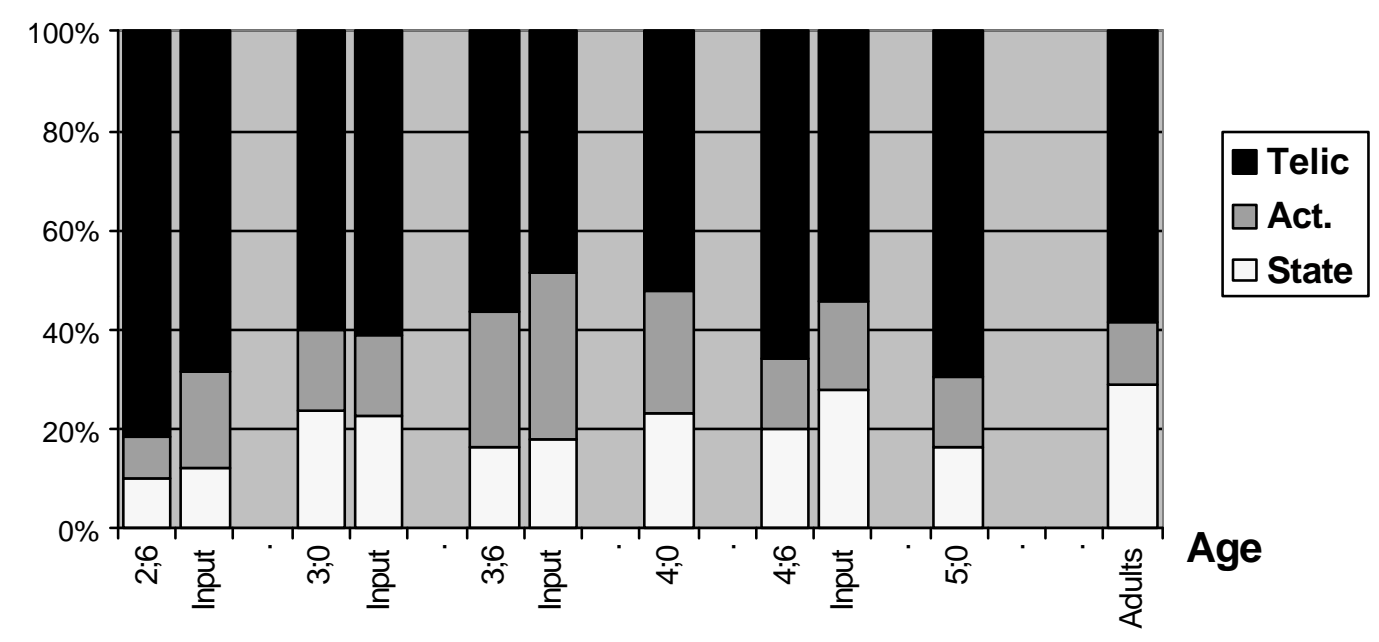

Figure 14: Input to Abe: proportion of situation types in Simple Past.

In the input to Abe at $2 ; 6\left(X^{2}=0,0247\right)$ the proportion of states in the input is significantly smaller than in the adult sample. In the input at $3 ; 6\left(X^{2}=8,09.10^{-5}\right)$ the proportion of activities is larger than in the adult sample. The other samples show no differences. There are no significant differences between Abe's language and the input language.

In summary, the distribution in the input can account partly for the distribution in child language. The association between Past tense and telic situations is stronger in the early input (Nina at 2;0). In many input samples the proportion of states is smaller and/or the proportion of activities larger than in the adult sample (Nina at 2;6 and 3;0, Abe at 2;6 and 3;6), which was also the case in child language (although not always in the same samples). The correlation between input and child language is high: there are no differences between Abe's language and the input. Nina's speech seems to differ from the input at 2;0 and 2;6: the proportion of telic situations in Nina's speech is larger than the input.

\subsubsection{Simple Present}

The results for the simple present are presented in Figures 15 and 16. 


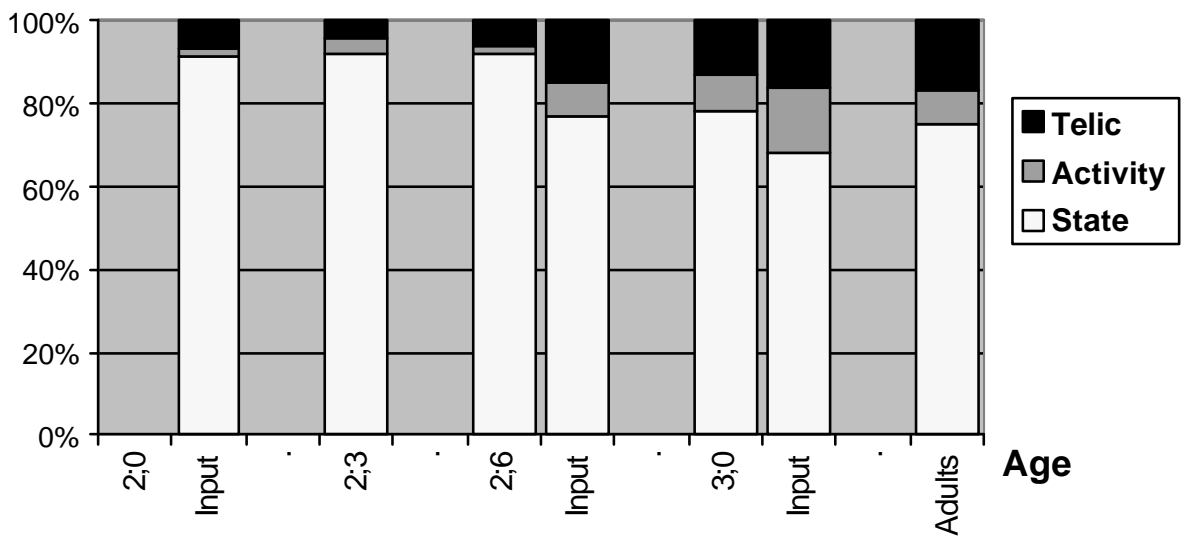

Figure 15: Input to Nina: proportion of situation types in Present.

In the input sample at 2;0 the proportions of activities and telic situations are smaller than in the adult sample $\left(\mathrm{X}^{2}=0,002534\right)$. At $2 ; 6$ there is no significant difference but at age 3;0 the difference with the adult sample is significant due to a large proportion of activities in the input $\left(\mathrm{X}^{2}=0,021121\right)$.

At $2 ; 6$, the language of Nina is significantly different from the input $\left(X^{2}=0,00747\right)$ because the proportion of states in Nina's speech is larger than in the input. At 3;0 there is no difference between input and child.

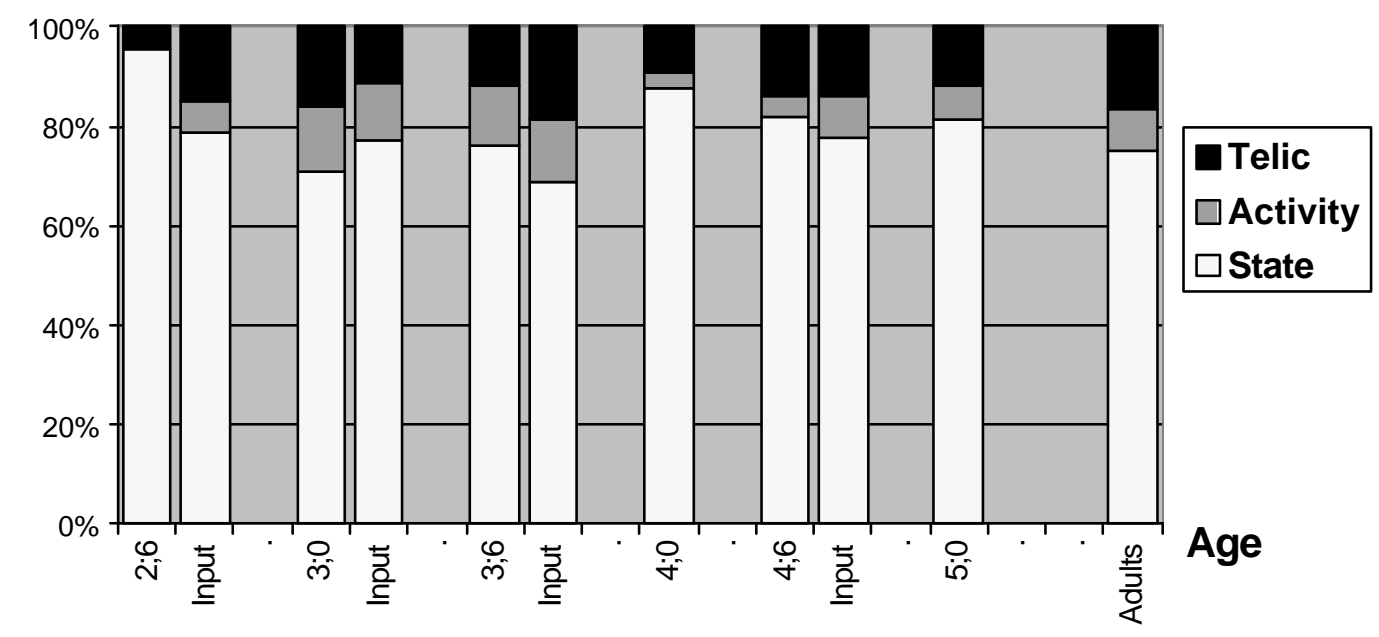

Figure 16: input to Abe: proportion of situation types in Present.

In the input samples, there are no significant differences with the adult sample. The language of Abe and of the input only differ at 2;6 (activities and telic situations have to be combined) $\left(\mathrm{X}^{2}=0,000761\right)$ : there are no activities in Abe's language and the proportion of telic situations seems to be smaller than in the input.

In summary, the distribution in the input partly accounts for the distribution in the child language. In the early sample (Nina at 2;0) the association between states and Simple Present is stronger in the input than in the adult sample. From age $2 ; 6$, both in the input to Nina and to Abe, the association between states and Simple Present is equal to the adult sample. However, in the input to Nina at 3;0, the proportion of activities is large.

Child language and input differ for both children at 2;6: the association between states and Simple Present is stronger in child language than in the input. From 3;0 years of age onwards, there is no longer a difference between input and child language. 


\subsection{Conclusion}

The results of Study III show that parents adapt their speech when talking to young children. The associations between tense/aspect morphology and situation type differ from what adults do when they speak to adults. There is a stronger association between Progressive and telic situations, a stronger association between telic situations and Past and a stronger association between Present and states. The association between Progressive and states and between Past and states is weaker and the association between Past and activities is stronger than in adultadult language.

This different distribution is the language addressed to children. It is the basis on which they build up their own language. The fact that the distribution in child language is skewed is thus not remarkable insofar as it is similar to the distribution in the input. Study III has shown that the correlation between input and child language is strong, and that the distribution in the input can account to a large extent for the distribution in child language: the strong association between Progressive and telic situations in a few samples, the strong association between telic situations and Past, and the small proportion of states in the Past and relatively large proportion of activities in the Past. There are, however, a few differences that cannot be accounted for by the input: although the association in the input to young children between Past and telic situations and between Present and states is stronger than in adult-adult language, these associations are even stronger in child language. Finally, the lack of telic situations in the Progressive in Nina 2;0 is not accounted for by the input.

It seems a logical consequence that the distribution in child language will differ from adult language when the language children hear is also different. Nevertheless, the questions remain why parents adjust their language directed to children and why the patterns in child language are not completely accounted for by the input.

\section{$5 \quad$ Explanations}

Several hypotheses have been posed for explaining the strong associations in child language between tense/aspect morphology and situation type. One of the explanations is the distribution in the input. As shown in section 4, the input can indeed account for the greater part for the distribution in child language. However, although the association between situations types and morphology in child directed speech is skewed compared to adult-adult speech, the association in child language is skewed even more. An explanation needs therefore to account for the differences between child-directed and adult-directed speech and between input and child language. First, the Defective Tense Hypothesis and the Prototype Account will be discussed. In section 5.3 an alternative hypothesis is proposed, the Discourse topic Hypothesis.

\subsection{Defective Tense Hypothesis}

The Defective Tense Hypothesis (e.g. Bloom, Lifter and Hafitz 1980, Bronckart and Sinclair 1973, Antinucci \& Miller 1976) claims that tense/aspect morphology at the early stages does not encode tense or aspect, but rather situation type. The observed patterns are then a consequence of cognitive limitations of the child who does not yet have a concept of temporal relations. Inflection is thus redundant in the early stage: it marks what is already inherently present in the semantics of the verb and its arguments. The first problem with this hypothesis is the question how and why a child would start to reanalyze the morphemes as tense/aspect markers instead of situation type markers. Furthermore, why would children grammatically 
encode situation type, although adult languages across the world in general lack grammatical encoding of situation type.

Shirai \& Andersen (1995:746) state that the Defective Tense Hypothesis could be viewed as an absolute statement - only telic verbs receive past inflections - or as a tendency - Past inflection is predominantly used with telic verbs. The less stringent version, however, entails that the child would apply different strategies at the same stage: whenever Past inflection is used with telic verbs, the child encodes resultant state or telicity, but what does the child do whenever the inflection is used with atelic verbs? Would the child then apply a different strategy, for example: encode tense or encode nothing? So in other words, if we accept a less stringent version of the Defective Tense Hypothesis, we would also have to accept that a child might have different semantic representations for the same morpheme: the one representation would hold with the one class of verbs and the other representation with another class of verbs. This is in fact what Bloom et al. seem to propose:

Although strongly influenced at the beginning by event-aspect, children are no doubt learning tense relations at the same time; they do not learn tense only after they learn aspect. (Bloom et al. 1980:407)

However, if inflection indeed functions as a marker for situation type, we would expect a regular system in the child language: one type of inflection for one class of situation types, one form for one function. However, as the child data show, the Progressive is from the start used for different situation types and the same holds for the Past in Naomi's and Abe's speech and the Present in Nina's and Abe's speech. Also during development, there is never complete regularity. So the same inflection can occur with different situation types and the same situation type can occur with different inflections. The findings go against an absolute version of the Defective Tense Hypothesis but a less stringent version would also assume regularity.

What is more, the findings are consistent with alternative explanations: the inflection could be part of an unanalyzed item, or, even though it occurs predominantly with one situation type, the inflection could nevertheless mark tense and aspect. There is no independent motivation that favors the encoding of situation type.

A final disadvantage of the Defective Tense Hypothesis is that it cannot account for the patterns we find in the input. The distribution in the input is also skewed and supposedly not because of a non-normative use of the inflections so why would parents change their language in this way?

\subsection{Prototype Account}

The Prototype Account (Shirai 1991, 1994; Shirai \& Andersen 1995) claims that children on the basis of distributional analysis create semantic representations of tense-aspect morphology that are restricted to the prototype of the morphological category. According to Li \& Shirai (2000:62-63) children acquire unanalyzed verbs during the first stage of language learning, on a verb-by-verb basis. Lexical representations during this stage consist of memories of past experiences. During the second stage, children notice repeated similarities in the formfunction mapping. They become aware of the fact that there are ontologically distinct types of situations. In the third stage children learn to map linguistic forms to these different situations: since parents for the majority use -ing to comment on ongoing activities, the child will create a prototypical semantic representation for the morpheme -ing, that is restricted to activities and semelfactive verbs, or in other words, to verbs that are characterized by the features [+dynamic, -telic]. The general meaning that -ing denotes would be 'Action in Progress' (Li \& Shirai 2000:66). Li \& Shirai assume that 
(...) children, on the basis of the comprehension of verb forms prior to active production, have already created a restricted semantic representation of morphological forms, even though their early morphology may appear as if it were entirely driven by lexical learning. (Li \& Shirai 2000: 64)

The Prototype Account is, however, not in every respect compatible with the data. According to Li \& Shirai's prototype of the Progressive it is to be expected that children would not or hardly use -ing for telic situations, neither with durative (accomplishment) nor with punctual (achievement) situations. The proportion of telic situations is, however, high in Nina at 2;3, Abe at 2;6, Naomi at 2;6 and 3;0 and also in the input to Nina at 2;3, and to Abe at 2;6 and $3 ; 0$.

Moreover, from a prototype view, the first inflected verbs heard in the input or the first inflected verbs used by the child must be prototypical examples of the situation types. However, the verbs in the input that are used with the Progressive are not all prototypical activities. Of all the Progressives used in the input, 54\% of all tokens is classified as [+dynamic, -telic], but $46 \%$ does not have one or both features. Besides, of all the types used with a Progressive, only 11 are classified as [+dynamic, -telic] and 13 miss one of the features. Furthermore, the first verbs that are produced with the Progressive do not all refer to 'prototypical' activities, that is to events with clear internal variation that need a constant input of energy. The first verbs that Nina uses with Progressive inflection (at 2;0) are hold sth. $(\mathrm{n}=4)$, sleep $(\mathrm{n}=4)$, move sth. $(\mathrm{n}=1)$, cry $(\mathrm{n}=1)$ and walk $(\mathrm{n}=1)$. Only move and walk would count as prototypical examples of activities. It is implausible that the child works from a (restricted) semantic representation 'action in progress' for the Progressive when the first examples in her own production are not prototypically dynamic.

The main objection to the Prototype Account lies however in the following assumption:

If children's semantic representation is restricted to this characterization, then whatever does not fit this characterization will not be given progressive marking at the early stage. (Li \& Shirai 2000:67, italics AB)

And, with respect to the Prototype of the Past, which is [+telic, +punctual, +result] according to Shirai and Andersen (1995):

As is typical of the prototype to non-prototype development, the restriction to prototype past (...) was gradually relaxed and at a later stage children started using the past tense for verbs lacking one of these features. (Li \& Shirai 2000: 68, italics AB)

Both citations suggest that the child might want to encode a certain verb with the Progressive or the Past, but does not do so because its semantic representation excludes the possibility of that specific combination. This implies that the semantic representations of children are rigid, and that the boundaries are strong. Nevertheless, the Prototype Account does explicitly not claim that the prototypical semantic representation leads to absolute skewing, but only to tendencies. The question then remains why children use non-prototypical combinations from early on.

A final problem of the Prototype Account is that it does not explain why parents would adjust their association between morphology and situation type when talking to children.

\subsection{Discourse Topic Hypothesis}

\subsubsection{Introduction}

Neither the Defective Tense Hypothesis nor the Prototype Account explains why parents change the way they talk when they talk to their children. Nor can they account for the 
findings in child language, that is that associations between morphology and situation type appear to be less regular or prototypical than would be expected on the basis of either hypothesis.

I propose an alternative approach, the Discourse Topic Hypothesis, that relies on the communicative and cognitive development of children. It can account for both the distribution in the adult language and the distribution in the child language and the differences between them.

First of all I assume that the acquisition of verbs and its inflection develops in a lexically based way, on a verb-by-verb basis, by learning which constructions are appropriate for which contexts (cf. Tomasello 1992, Lieven, Pine \& Baldwin 1997, Pine, Lieven \& Rowland 1998). Children will acquire first what are prototypical uses of specific verb-morpheme combinations. The more experience they have with certain forms in certain contexts, either in production or in comprehension, the earlier they will be acquired. What children will gradually grasp is the effect one creates when adding an inflection to a verb-stem, thus for the ending -ing the situation is understood as ongoing, without its boundaries being entailed. So, the Progressive does not mean 'action in progress'; it effectuates the presentation of a situation as in progress.

There are no prototypical meanings of a morpheme (such as there are prototypical members of classes), but there are prototypical or unmarked uses of morphemes. The prototypical uses are the most relevant combinations. It is for example relevant to present a dynamic situation or a temporary state as ongoing, whereas this is not relevant for a state, since a state is inherently ongoing and without boundaries. ${ }^{4}$ Furthermore, it is relevant to mark a telic situation by a Simple Past, since it not only indicates that the situation was actual at a period in time prior to utterance time, but it also entails that the end-state has been reached and that a certain change in the real world has taken place. If states and activities are marked by a Past, it only indicates that the specific state or activity held at a moment in the past, but no resultant effect is implied.

Certain combinations of morphology and situation type are thus relevant, while others are less relevant or even semantically odd. This is determined on the one hand by the conceptual representation of the real world situation that a verb and its arguments refer to and on the other hand by the conceptual representation of the effect produced by grammatical elements. The relevance of particular combinations between morphology and situation type is however dependent on the discourse topic. I will argue that for the discourse topics that young children talk about, especially the unmarked combinations of tense/aspect morphology and situation type are most relevant.

\subsubsection{Relevant combinations}

Which combinations of tense/aspect and situation type are relevant for which discourse topics? There are at least three general discourse topics in which English speakers make use of Progressives, Simple Past, or Simple Present ${ }^{5}$ :

- Talking about the here-and-now

- Describing past events

\footnotetext{
4 It is only relevant to present a state as ongoing when the speaker wants to stress that the state is temporary and controlled (for example 'being mean' vs. 'be mean') (Smith 1991).

5 This analysis is a simplification of the facts, but it suffices for the point I want to make in this section.
} 
- Giving general comments on the world, such as generic statements, habituals, social rules, laws etcetera.

\subsubsection{Talking about the here-and-now}

First of all, when speakers of English wish to talk about the here-and-now, to describe observable events or states, whether visible, audible or sensible, they need the following combinations:

- for describing a state (except temporary states): Simple Present

- for describing temporary states (position verbs, hold, wait, etc.): Progressive

- for describing an activity: Progressive

- for describing a telic situation that has not yet ended: Progressive

- for describing a situation that has just ended (immediate past): Simple Past

With respect to the last point: situations that have just ended are mostly relevant to the hereand-now when they have created a change in the world: these are described by telic situations. Furthermore, situations that take just a moment in time to happen, are already ended before one can talk about it. They can only be referred to by a Past. So when talking about the hereand-now, the combination between Past and telic situations that have just ended (in particular punctual telic situations) is highly relevant.

\subsubsection{Describing past events}

When a speaker of English wants to describe an event from the past, the following combinations are relevant:

- Simple Past for states (except temporary States)

- Simple Past for temporary states (position verbs, wear, hold etc.), activities and telic situations that are anterior to Topic Time ${ }^{6}$

- Past Progressive for temporary states (position verbs, wear, hold etc.), activities and telic situations that overlap Topic Time

The speaker needs a sophisticated use of perfective and imperfective forms in order to construct the order of events that he wants, to indicate simultaneity, anteriority or posteriority between different (parts of) events of the past. $^{7}$

\subsubsection{Commenting on the world as it is}

When a speaker of English wants to give general comments on the world as it is, he needs:

- Simple Present for states, activities and telic situations

Furthermore, conditional clauses are an important means to formulate a general statement about the world.

In summary, in the setting of talking about the here-and-now, a speaker of English needs the unmarked combinations of tense/aspect morphology and situation type and the Progressive for telic situations that have not yet ended. In the settings of talking about past events and

6 Topic Time is the notion introduced by Klein (1994) that refers to the time span about which the speaker asserts something.

7 Of course other forms, like the Present, Past or Future Perfect play a part in describing past events, but they do not form part of this study. The use of Present tense forms for describing past events which creates a vivid narrative style is also left out of consideration. 
talking about the world as it is, a speaker of English not only needs the unmarked, but also the marked combinations of tense/aspect morphology and situation type, although even in those settings the unmarked combinations prevail.

\subsubsection{Children's Development}

Assuming that children at first either mainly wish or are able to communicate about the hereand-now (cf. Brown \& Bellugi 1964), then they will at first only or mainly make use of unmarked combinations of tense/aspect morphology and situation type. Those are the only forms they need for this type of communication and therefore the only forms they acquire. Depending on their general cognitive development children will increasingly be able, need or wish to talk about past events that they remember ${ }^{8}$ and they will increasingly contemplate about and comment on the world. It is a chicken and egg question whether cognitive development is responsible for the topics about which the children talk with their parents or whether the experience with and communication about different topics influences the cognitive development. These are probably strongly intertwined (cf. Johnston 1985, Bowerman \& Levinson 2001).

Children do not exclude 'marked' combinations on semantic grounds or because of grammatical rules. Because of the discourse topics children talk about - which is related to their cognitive development - children less often need to use marked combinations. Since parents adapt the topics they talk about to the cognitive level of their children, the input language will show similar distributions as the child language: only the unmarked combinations are used. However, the communicative wishes of parents may be slightly ahead of the child's capacities: they start to talk about past events, to make statements about the world as it is, before the child is actively doing so, hence using more marked combinations than the child.

\section{Study IV: Discourse topics}

In order to find out whether the discourse topics of children indeed develop from only talking about the here-and-now to talking about past events and talking about the world as it is, a qualitative analysis is carried out on the data of Nina and Abe and the input to them. Besides that, the data of Sachs (1983) on the use of Past inflection by Naomi and her parents is used. It is investigated for what discourse topics children use their Progressives, Present and Past forms. What do the parents do in the input? And what happens in the adult-adult conversations?

\subsection{Progressive}

Speakers of English need the Progressive when they want to talk about the here-and-now, about observable events that are temporary states, activities or not-ended telic situations. They also need the Progressive when they want to describe past events; the Past Progressive in combination with a temporary state, activity or telic situation yields the reading that the situation overlaps Topic Time.

Talking about objects or events not in the here-and-now is labeled „displacement“ by Hockett (1960). The tendency of children to rely less and less on the here-and-now in speaking and understanding is called decontextualization by Bates (1979). 


\subsubsection{Progressive for talking about the here-and-now}

The children and their parents very frequently use the Progressive for talking the here-andnow: they continuously describe what the child is doing itself or what a sibling, a pat, a toy figure, or a figure on a picture is doing. In the beginning, the Progressive in the input is only used for talking about the here-and-now. It is used with all the appropriate situation types, depending on the activities the child is involved in:

*MOT: he's holding something in his hand (state)

*MOT: what is the king wearing on his head? (state)

*MOT: who's sleeping? (activity)

*MOT: you're drawing with your finger? (activity)

*MOT: are you closing the door? (telic)

*MOT: you're turning his head around? (telic)

*MOT: what are you drawing? (telic)

*MOT: are you putting the stethoscope on your ear? (telic) (Nina, 2;0)

Also the children use the Progressive for talking about the here-and-now from the start. They use the Progressive spontaneously in all relevant combinations, with temporary states, activities and telic situations that have not yet ended, depending on their activities:

*CHI: Little girl waiting (state: picture)

*CHI: Her not eating (activity: picture)

*CHI: Her drinking (activity: picture)

*CHI: I making train for you (telic: own action)

*CHI: bear going San Francisco. (telic: playing)

*CHI: I putting it in the plate (telic: own action)

*CHI: climbing up on the tree (telic: picture)

(Nina, 2;3)

Note that the main functional difference between the input and the child's speech is that Nina uses declarative utterances, whereas the mother mainly uses interrogatives.

As often as children and their parents use the Progressive for talking about observable events, as rarely adults among themselves use the Progressive for this purpose. In the adult corpus ${ }^{9}$, examples in which the Progressive is used for talking about the here-and-now are hard to find:

*LYN: but she must only -- .. < What is $\mathrm{m}-\ldots$ blowing out of there $>$.

*MAR: What's everybody waiting for. You guys are supposed to go home now.

*LEN: Oh, you're kidding .

(SBCSAE)

As opposed to children and their parents, describing their own or other's activities is something adults among themselves hardly ever do. The Present Progressives that adults use are mainly used for situations that are ongoing but not observable (not in the here).

\subsubsection{Progressive for describing Past events}

After the stage in which the Progressive is only used for describing observable events in the here-and-now, the Progressive is used for describing past events by using a past copula. It does not only indicate that the situation took place prior to utterance time, but also that it

9 Examples taken from the SBCSAE are presented in a simplified way for matters of readibility. 
overlaps with Topic Time. This use of the Progressive only comes in gradually. It occurs first in the input, but very infrequently, and only in the later samples the children start using it themselves, on their own initiative. The first use of a Progressive for describing a Past event occurs in the input. Nina responds to it in a proper way but looses interest quickly:

*MOT: you saw a big fish there?

*CHI: on me [//] on the water.

*MOT: in the water?

*CHI: $\quad$ yup [= yes].

*MOT: what were they doing?

\%com: Nina looses interest in talking about the aquarium. she goes over and looks in her box of doll house furnishings. she is looking for some pots and other equipment to cook and eat with.

*MOT: what were the fish doing?

*CHI: where's my pot?

(Nina, 2;3)

So, in the input, the Progressive is already used for describing past events, while in the child speech it is not. Only at age 3;0 Nina uses a Progressive for describing a past event. Twice, the mother takes the initiative and twice Nina describes a past event by using the Progressive on her own initiative. One example of each is presented below:

Situation: Looking at photographs

*MOT: what's this on the floor?

*CHI: a mat.

*MOT: oh \# what were we doing on that mat?

*CHI: eating?

*MOT: oh

*MOT: the grownups were eating on the table or on the floor?

*CHI: on the floor.

*CHI: and kids were eating on the table.

*MOT: I see.

(Nina, 3;0)

*CHI: the doggie's sharing it.

*CHI: he bite his tongue while he was eating.

*CHI: and so he's gonna have a little rest with his blanket on. (Nina, 3;0)

The same pattern occurs in Abe's data. In the input at 2;6, the Progressive is (infrequently) used for describing past events, while Abe does not yet use it for this purpose:

*CHI: Mama \# what happen?

*MOT: I was showing Dad my owie. (Abe, 2;6)

*CHI: don't go please please don't go.

*FAT: I was just teasing. We're not going anywhere.

(Abe, 2;6) 
Although Abe uses the Progressive from the beginning to talk about observable events, the first time that he uses the Progressive for talking about past events is at 3;0:

*FAT: what did you say?

*CHI: nothing, I was talking by myself.

(Abe, $3 ; 0)$

*CHI: pretty soon a big spaceship will crash on your head.

*FAT: on my head?

*FAT: I hope not. Oh \# I'm so scared help!

*CHI: I was teasing. It will not crash on your head.

*FAT: oh what a relief.

(Abe, 3;0)

In the same sample, Abe uses the Progressive and Simple Past in a sophisticated way for describing the sequence of different past events:

*CHI: Remember when a long time ago (...) while you were playing ball with a striped ball mommy maked ... cutted a hole out of that trash thing then then I was playing basketball and then the basketball got brokened.

(Abe, 3;0)

Adults among themselves rather often use the Progressive for describing a past event. Of all the Progressives in the adult sample, $28 \%$ is a Past Progressive. Of all the Progressives that the children use and that are used in the input, the percentage of Progressives used for describing a past event is in the beginning very low or even absent, as shown in Table 2:

\begin{tabular}{cccccc}
\hline Age & Naomi & Nina & Input & Abe & Input \\
\hline $1 ; 6$ & 0 & & & & \\
$1 ; 9$ & 0 & & & & \\
$2 ; 0$ & 0 & 0 & 0 & & \\
$2 ; 3$ & 5 & 0 & 5 & & \\
$2 ; 6$ & 0 & 0 & 2 & 0 & 6 \\
$3 ; 0$ & 0 & 9 & 13 & 15 & 9 \\
$3 ; 6$ & & & & 32 & 53 \\
$4 ; 0$ & & & & 17 & n.a. \\
$4 ; 6$ & & & & 24 & 13 \\
$5 ; 0$ & & & & 29 & n.a. \\
\hline
\end{tabular}

Table 2: Percentage of Past Progressive (of all the Progressives).

\subsubsection{Summary}

In summary, Progressives are mainly used for describing observable events in child language and in input to children. In adult-adult conversation on the contrary the Progressive is hardly ever uses for describing observable events. The distribution of situation types over the Progressive in the early child samples and the input can be accounted for by the combinations that are needed for talking about the here-and-now. The favourite activities of children and their parents determine what they will speak about most. The large proportion of telic situations in the child language and input is simply a matter of coincidence: in the particular samples the child or a third person is involved in many telic situations, such as drawing, writing, building or making something, going somewhere, putting something somewhere, opening or closing things, climbing up on things etcetera. Since everything the child does is mentioned in the early stages, many telic situations are used with the Progressive. Adults may 
also be involved in those type of activities, but they simply do not describe what they are doing.

When children grow older, they gradually use the Progressive less to talk about the here-andnow and more to describe past events. This development is first noticeable in the input and is followed by the child. Adults use the Progressive for describing past events rather often $(28 \%)$.

\subsection{Simple Past}

A speaker of English needs the Simple Past for talking about the here-and-now, i.e. events that have just happened in the immediate past, and for describing past events. For the first purpose, the Past is most relevant in combinations with telic situations that have just been completed. In particular telic, punctual situations happen so quickly that one can only talk about it when they have already ended. For the second purpose, the Past can be combined with all situation types, but also prevails with telic situations.

\subsubsection{Simple Past for talking about the here-and-now}

Like the Progressive, the Past is in the beginning mainly used by children and their parents for talking about observable events. In the input, from the very beginning, the Past forms are used for describing observable events of the immediate past. The below examples are all from Nina $2 ; 0$ :

\%com: Nina bumps into her mother

*CHI: sorry.

*MOT: did you bump into me?

(Nina, 2;0)

\%com: noise of toys falling off Nina's chair

*CHI: a toys down.

*MOT: all the toys fell off the chair \# didn't they? $\quad$ (Nina, 2;0)

\%com: elastic string of Nina's birthday hat snaps and hurts her. Nina cries.

*MOT: oh \# did the elastic hurt you?

*CHI: $\quad$ yeah $[=$ yes]. $\quad$ (Nina, 2;0)

According to Sachs (1983), Naomi started using past markings at 22 months. Until 26 months, they were only used to refer to observable events of the immediate past. The Past forms are used spontaneously. Examples are:
*CHI: I throwed it
(Naomi, 2;0)
*CHI: Georgie fell down? $\quad$ (Naomi, 2;0)

Also Abe uses the Past spontaneously for describing observable events from the first sample onwards:

*FAT: ok \# hold on.

*CHI: I falled@n down.

*FAT: you sure did. You sure are a ticklish Batman. (Abe, 2;6)

*CHI: $\quad$ uhhuh Momma \# come see this ladder \# I made. $\quad$ (Abe, $2 ; 6)$ 
*CHI: oh Mom \# my daddy doesn't want to!

*CHI: he said no. (Abe, $2 ; 6)$

*MOT: Abe \# do you want to help me do dishes?

*FAT: ok \# hold on.

*CHI: uhhuh \# I'll put it in

*CHI: I got a thing in there

*CHI: it dropped!

*MOT: uhhuh it fell into the water now I'll be able to wash it. (Abe, 2;6)

Nina's use of Past forms starts unexpectedly. In the sample at 2;0, she uses gave eleven times. It is the only Past form she uses. It is only used in the context of talking about who gave which present to her at her birthday, the day before the recording. Mother and child talk about this a lot in this fragment looking at or playing with the presents:

*MOT: who sent the picture of the lion to Nina?

*CHI: miss \# miss gave it.

*CHI: Mrs. Wood.

*MOT: not Mrs. Wood \# nonna.

*CHI: Nonna gave it.

\%com: Nina is looking at the picture of the horse.

*CHI: Betta \# Betta gave it.

*MOT: Betta gave you the picture of the horse.

*CHI: Nonna gave a horse.

*MOT: no \# Nonna gave the picture of the lion to Nina.

$* \mathrm{CHI}: \quad$ yeah $[=$ yes $]$.

(Nina, 2;0)

Although the 'giving' happened in the earlier past, the presents are in the here-and-now. This instances can neither be classified as clear examples of talking about past events, nor as examples of talking about the here-and-now.

Despite the unexpected use of the Past in the first sample, the other samples show that Nina uses the Past for describing here-and-now more often than for describing past events. In the sample at 2;3, both forms Nina uses describe events that have just happened. At 2;6, of all the past forms $(n=14)$, eight describe an observable event (mainly 'falling'), four are used for describing a past event and two are unclear. At 3;0, the distribution is the other way around: of all the past forms $(n=43)$, only 12 are used for describing an observable event, while 27 are used for describing a past event and 4 are unclear.

As opposed to children and their parents, adults talking to adults hardly ever use Past tenses for talking about observable events. There are some examples in the data, but they are scarce:

*MRL: ... Oops, sorry. ... Did I get you?

*KVN: Did you notice the room got deathly silent when Kendie mentioned marriage?

*DAR: Bit your teeth, hunh?

(SBCSAE)

According to Sachs (1983:17), adults mainly report something that has just happened to another adult because the addressee has not noticed the event - like you dropped your scarf whereas in child directed speech the Past is often used for commenting on or asking about an activity the child has just performed. The examples in the adult data of this study show that adults also use the past in order to check what has just happened. 


\subsubsection{Simple Past for describing past events}

From the beginning the Past in the input is frequently used for talking about the here-andnow. However, from early on, parents use the Simple Past now and then for talking about past events. At first, the children often do not respond in a pragmatically adequate way:

*CHI: oh \# poor lamb.

*MOT: what happened to the lamb?

*CHI: uh \# take him.

\%act: hands the lamb to her mother

(Nina, 2;0)

Sometimes children do respond in a pragmatically adequate way, but not in a formally adequate way:

*MOT: and what happened to your dolly?

*CHI: bite that.

\%com: Slurred

*CHI: that.

*MOT: did the dog bite your dolly?

*CHI: yeah [= yes].

*MOT: and what happened to the dress?

*CHI: here.

*MOT: did the dress get torn by the dog?

*CHI: yeah [= yes].

*MOT: bad dog.

*CHI: bad dog.

(Nina, 2;0)

These findings are in accordance with Sachs (1983:18-20) who also reports talking about past events by Naomi's parents as early as 22 months. Often, Naomi responded to these initiatives with unrelated responses or with imitations.

According to Sachs (1983), Naomi starts using the Past to refer to events that had happened on the same day at 26 months. At 32 months Naomi begins to make spontaneous reference to past experiences. Until then Naomi hardly ever expressed the meaning Earlier Past on her own initiative (Sachs 1983:19). Of the 253 past references in Naomi's speech up till 29 months of age, only twice, at 26 and at 29 months, Naomi spontaneously mentions an event of the past.

The same patterns can be found in Nina's and Abe's speech. Although they use past forms for describing past events from quite early on, they use it less infrequently, only in short fragments, and mainly as response to their parents:

*CHI: I have a band aid.

*MOT: why \# what happened?

*CHI: a hurt \# hurt me.

*MOT: when did you hurt yourself?

*CHI: when me hurt meself

*MOT: when did you hurt yourself? yesterday?

*CHI: yup

*MOT: who put the band aid on?

*CHI: Gail did.

(Nina, 2;6)

Only in a few examples, the children talk about past events on their own initiative: 
*MOT: oh \# Gail has a swimming pool \# doesn't she?

\%com: Gail is a baby-sitter of Nina's. Nina had fallen into her large swimming pool several months ago.

*CHI: I fell in it.

*MOT: did you fall in Gail's swimming pool?

*CHI: yup [= yes].

(Nina, 2;6)

*FAT: you're the one who burned yourself last time \# Abe I warned you not to touch the hot pan.

*CHI: I cried \# right?

*FAT: you sure did.

(Abe, 2;6)

*CHI: remember a long time ago when Mommy was also at school? We played with this and it got brokeded and then the top came and then the marble comed out and then we played with it right?

(Abe, 3;0)

As opposed to children and their parents, adults among themselves mainly use the Past forms for communicating about past events. They talk about it frequently and extensively as the next example shows:

*KVN: You guys won't believe what happened to us in the parking lot of the mall the other day.

*WEN: Oh. by the Goodwill store.

*KVN: ... Some guy came out and he_ he was, he was trying to sell us cologne

*WEN: No, he wasn't trying to sell us cologne,

*KVN: Well it_ _ No=, I guess he was trying to like, lure us to a .. place where they would sell, like, .. imitation cologne, but he said, it's not imitation, because,

*KVN: because it's= made by the same people, but it's put in different bottles? (SBCSAE)

\subsubsection{Summary}

At first, both in the input and in child language, Past inflection is mainly used for talking about the here-and-now, for describing events that have just ended. In this setting, the most relevant combinations is with telic situations. Rather early parents also start using the Past for describing past events but the responses of the children are often not yet pragmatically or formally appropriate. Gradually, children start using the Past inflection spontaneously for describing past events. The distribution of the two functions is however not equal to adultadult conversation. In adult-adult conversation the Past is for the greater part used to talk about past events, whereas in child language and in the input the Past is in the beginning for the greater part used for describing observable events.

The development of discourse topics can indeed account for the distribution of Past tense morphology and situation type. Since it is most relevant to mark telic situations that have just been completed in the setting of talking about the here-and-now, this combination highly prevails in the younger samples of children. Only when talking about past events does become more frequent, there is more opportunity to use the unmarked combinations. Since parents already start mentioning past events before the children do so regularly, the skewing in the input data is less strong than in the child data.

One point to note is that the proportion of Past in combination with states in both child and input language was small compared to the adults. This could be explained by the fact that the 
fragments about past event in child language and input are not as elaborated as they are in adult-adult conversations. Since states often function as background information in describing past events, they might just be less relevant for the communication between children and their parents. In the beginning the past events are often shared memories about dynamic situations the child has participated in or state-changes that have taken place. In contrast, adults also describe the mental states they were in.

\subsection{Simple Present}

Speakers of English need the Simple Present when they want to describe a state that holds in the here-and-now and when they want to give general comments on the world as it is.

\subsubsection{Simple Present for talking about the here -and-now}

In the input, the Simple Present is from the beginning used for talking about the here-andnow:

*MOT: he's a nice little lamb.

*CHI: got one ear.

*CHI: got one ear.

*MOT: he has one ear?

(Nina, 2;0)

*MOT: you want Mommy to have the chair on her hand?

(Nina, 2;0)

*MOT: I think he's a dog.

(Nina, 2;0)

*MOT: that looks like cereal to me.

(Nina, 2;0)

In the first sample in which Nina uses Simple Present forms, they are always used for talking about the here-and-now. Nina uses them on her own initiative.

$\begin{array}{ll}* \mathrm{CHI}: & \text { I want applesauce } \\ * \mathrm{CHI}: & \text { You want more? } \\ * \mathrm{CHI}: & \text { I need the bottle } \\ * \mathrm{CHI}: & \text { I think dolly's thirsty. } \\ * \mathrm{CHI}: & \text { I 've a honey book. }\end{array}$

(Nina, 2;3)

The same pattern holds for Abe and his parents.

Adults talking to adults also use the Simple Present for describing the here-and-now, but less frequent than children and their parents:

*DAR: No I I don't want to hear anything out of a book with, .. chapter called heaven and hell.

*MRL: I have ... the ideal ... makings .. for garlic bread. Right here, right.... Well actually I have Trader Joe's, <VOX whipped ... garlic bread .. spread VOX $>$.

*MRL: ... I got .. fishy hands.

(SBCSAE)

\subsubsection{Simple Present for commenting on the world}

The Simple Present can also be used for making general statements about the world. For this purpose, besides the combinations with states, combinations with activities and telic situations are relevant. In the input the Simple Present is used for making general statements about the 
world from the beginning, but infrequently. The child does not respond to it in a pragmatically adequate way:

*MOT: want me to make the nurse sit down?

*CHI: yeah [= yes].

*MOT: how do I make the nurse sit down?

\%com: Nina looking at the book "sleeping beauty". she calls sleeping beauty "goldy."

*CHI: goldy. (Nina, 2;0)

It is at 2;6, in the context of scaffolding, that Nina produces a Simple Present for the first time that is used for making a general statement about the world:

*MOT: What do you do when you swim? Do you splash a lot?

*CHI: Yeah

*MOT: You do? Do you get wet?

*CHI: yup, I get ... I don't.

(Nina, 2;6)

It is only at 3;0 that Nina herself takes the initiative to make a general statement about the world as it is by using a Simple Present.

*CHI: don't you make the dog fall down.

*MOT: I didn't mean to knock him over.

*CHI: cause he cries every day when you push him down.

(Nina, 3;0)

Abe also uses the Simple present for the first time for making a general statement in the sample at 3;0.

*CHI: I didn't know grandmas smoke cigarettes.

(Abe, 3;0)

In the later samples there are many examples in which the Present is used for making general statements about the world:

*CHI: How do bees grow their babies?

(Abe, 3;6)

*CHI: Mommy \# I have a good thing to catch mosquitoes. You get a pin, a sharp pin and then you put it in the mosquitoes then you kill the mosquitoes. (Abe, 3;6)

Adults as opposed to young children and parents talking to young children, frequently use the Simple Present to make claims about the world as it is. Therefore, they need the marked combinations more often than children and their parents. These remarks are often constructed in a conditional clause.

*LYN: .. sometimes if you get one that's been thawed out a little bit, .. they start really stinking and stuff. Oh, it's the grossest thing.

*MAR: .. Why do these ca=ns, .. get so warped. Only the --.. Only the Sam's Club cans .. get so warped.

*DAR: you know, you ask someone why they're interested in electronics, and they can probably tell you.

(SBCSAE)

\subsubsection{Summary}

At first, the Present is only used for talking about the here-and-now and only later on, children start commenting on the world. Only in the latter context, the marked combinations are needed. Since the parents start commenting about the world in the input before their children do so, the skewing in the input is less strong than in child language. 


\subsection{Conclusion}

The qualitative analysis of the discourse topics in child language, input and adult-adult data supports the Discourse Topic Hypothesis. At first, children and their parents mainly converse about the here-and-now, about observable events and events that have just happened. As a consequence they only need to use unmarked combinations of tense/aspect morphology and situation types. The activities the children are involved in determine which combinations are used.

Talking about past events develops later on. Although a few Past forms in the early samples are already used by the child for describing Past events, the frequency is low and in most cases it is the parent who takes the initiative and helps the child to talk about the earlier past by way of scaffolding. Only later on, the child starts talking about past events more frequently and spontaneously. The description of past events is often short and concerns shared memories. This makes the use of states in the Past for presenting background information less relevant. Furthermore, the sophisticated sequencing of (parts of) events in the past is not yet mastered by young children. This might account for the late appearance of the Past Progressive: activities and temporary states in the Past Progressive are mainly used for describing simultaneity between different situations in the past. Children's descriptions of past events, however, are in the beginning not yet so elaborate.

Finally, children start making general statements about the world as it is. Only then, the marked combinations of Present inflection with activities and telic situations are needed. In the beginning it is the parent who takes the initiative to talk about the world and by way of scaffolding, the child is able to respond adequately. Around age 3;0 children start commenting on the world spontaneously.

As opposed to children and their parents, adults among themselves mainly converse about past events or the world as it is; they rarely talk about the here-and-now.

\section{Conclusion}

On the basis of a comparison between adult-adult language, child language and input to the children it was established that in general the association between Past and telic situations and between Present and states was stronger in the input and even stronger in child language than in adult English. For the Progressive it was found that the association between Progressive and activities was not stronger in the input and in child language than in adult-adult language but the association between Progressive and telic situations was remarkably high in input and child language at certain points.

To a large extent the input can explain the distribution of tense/aspect morphology and situation type. There is no need to assume that children work from a semantic representation or a rule for the tense/aspect morphology they use. Both the Defective Tense Hypothesis (rule-based learning) and the Prototype Account (semantic representation) predict that children would have a regular system in the beginning, but the findings are not compatible with this expectation. A lexically-based development in the beginning can explain best the irregularities found in the combinations of tense-aspect morphology and situation type in child language.

Furthermore, neither the Defective Tense Hypothesis nor the Prototype Account explains why the distribution in the input is different from adult-adult conversation but not so different as the distribution in child language. 
The Discourse Topic Hypothesis claims that the discourse topic is of influence to the distribution of tense/aspect morphology and situation type. When talking about observable events, the unmarked combinations - Progressive and temporal states, activities and not ended telic situations, Present and states and Past and telic situations - are most relevant. When talking about Past events or when commenting on the world, marked combinations are also relevant, although the unmarked combinations still prevail. Assuming that children at first mainly talk about the here-and-now and their parents as well, they at first only need the unmarked combinations.

Independent evidence for the Discourse Topic Hypothesis was collected by a qualitative analysis of what children talk about on their own initiative, what parents talk about to their children and what adults talk about among themselves. It was shown that children in the early samples mainly or only talk about the here-and-now, about observable events. Their parents do so equally, but they also talk about past events now and then and sometimes about the world as it is. By contrast, adults in interaction with adults, hardly ever talk about observable events: they mainly talk about past events or about the world as it is. Accordingly, different distributions of tense/aspect morphology and situation types are needed and used by children, parents talking to their children and adults talking to adults. Due to cognitive and communicative development, children and their parents increasingly talk about past events and about the world as it is. As a consequence, they need more marked combinations and the patterns of association between tense-aspect morphology and situation type gradually become adult-like.

This study shows the importance of investigating not only child language or input, but also the final stage (adult-adult conversation). It appears to be useful to investigate which linguistic constructions and combinations are needed for what discourse topics. On the basis of the development of discourse topics of children and their parents, the distributional patterns in child language and input could be accounted for.

\section{References}

Aksu, A. (1978): Aspect and modality in the child's acquisition of the Turkish past tense. Ph.D. dissertation, Department of Psychology, University of California, Berkeley.

Aksu-Koç, A. (1988): The Acquisistion of Aspect and modality: The Case of Past Reference in Turkish. Cambridge, UK: Cambridge university Press.

- (1998): The role of input vs universal predispositions in the emergence of tense-aspect morphology: Evidence from Turkish. First Language 18, 255-280.

Andersen, R. \& Y. Shirai (1996): Primacy of aspect in first and second language acquisition: The pidgin/creole connection. In W.C. Ritchie \& T.K. Bhatia (eds.): Handbook of Second Language Acquisition. San Diego, CA: Academic Press.

Antinucci, F. \& R. Miller (1976): How children talk about what happened. Journal of Child Language 3, 169189.

Bates, E. (1979): The emergence of symbols: Cognition and commincation in infancy. New York, Acadamic Press.

Bloom, L, K.Lifter \& J. Hafitz (1980): Semantics of verbs and the development of verb inflection in child language. Language 56, 386-412.

Bowerman, M. and S.C. Levinson (eds.) (2001): Language acquisition and conceptual development. Cambridge: Cambridge University Press.

Bronckart, J. \& H. Sinclair (1973): Time, tense and aspect. Cognition 2, 107-130.

Brown, R. \& U. Bellugi (1964): Three processes in the child's acquisition of syntax. Harvard Educational Review 34: 133-151. 
Clark, E.V. (1996): Early verbs, event-types, and inflections. In C.E. Johnson \& J.H.V. Gilbert (eds.): Children's Language, Vol. 9. Hillsdale, NJ: Lawrence Erlbaum.

Comrie, B. (1976): Aspect. Cambridge, UK: Cambridge University Press.

Dik, Simon C. 1997. The theory of Functional Grammar. Part I: the structure of the clause. Kees Hengeveld (ed.) $2 \mathrm{~d}$ rev. ed. Berlin: Mouton de Gruyter.

DuBois, J.W. (ed.) (2000): Santa Barbara Corpus of Spoken American English, Part 1. 3 CD-ROMs. Philadelphia: Linguistic Data Consortium.

Erbaugh, M. (1978): Acquisition of temporal and aspectual distinctions in Mandarin. Papers and reports on child language development 15, 30-37.

Hockett, C.F. (1960): The origin of speech. Scientific American 203, 89-96.

Johnston, J.R. (1985): Cognitive Prerequisites: The Evidence fro m Children Learning English. In D.I. Slobin (ed.): The crosslinguistic study of language acquisition: Vol. 2. Theoretical issues. Hillsdale, NJ: Lawrence Erlbaum Associates.

Klein, W. (1994): Time in Language. London: Routledge.

Kuczaj, S. (1977): The acquisition of regular and irregular past tense forms. Journal of Verbal Learning and Verbal Behavior 16, 589-600.

Li, P. \& Y. Shirai (2000): The acquisition of Lexical and Grammatical Aspect. Berlin/New York: Mouton de Gruyter.

Lieven, E., Pine, J.M. \& Baldwin, G. (1997): Lexically-based learning and early grammatical development. Journal of Child Language, 24, 187-219.

MacWhinney, B. (1995): The CHILDES Project: Tools for Analyzing Talk. 2nd edition. Hillsdale, NJ: Erlbaum.

MacWhinney, B. \& C. Snow (1985) : The Child Language Data Exchange System. Journal of Child Language 12, 271-296.

- (1990): The Child Language Data Exchange System: An update. Journal of Child Language 17, 457-472.

Pine, J., E. Lieven, \& C.F. Rowland (1998): Comparing different models of the development of the English verb category. Linguistics 36, 807-830.

Sachs, J. (1983) : Talking about the there and then: The emergence of displaced reference in parent-child discourse. In K. E. Nelson (ed.): Children's Language, Vol. 4. Hillsdale, NJ: Lawrence Erlbaum.

Shirai, Y. (1991): Primacy of aspect in language acquisition: Simplified input and prototype. Ph.D. dissertation, Applied Linguistics, University of California, Los Angeles.

- (1994): On the overgeneralization of the progressive marking on stative verbs: Bioprogram or input? First Language 14, 67-82.

- (1998): Inherent aspect and the acquisition of tense/aspect morphology in Japanese. In H. Nakajima \& Y. Otsu (eds.): Argument structure: Its Syntax and Acquisition. Tokyo: Kaitakusha.

Shirai, Y. \& R.W. Andersen (1995): The acquisition of tense-aspect morphology: A prototype account. Language 71, 743-762.

Smith, C. S. (1991): The Parameter of Aspect. Dordrecht: Kluwer.

Stephany, U. (1981): Verbal grammar in Modern Greek early child language. In P. S. Dale \& D. Ingram (eds.): Child language: An international Perspective. Baltimore, MD: University Park Press.

- (1997) The acquisition of Greek. In Dan I. Slobin (ed.), The Crosslinguistic Study of Language Acquisition, Vol. 5: Expanding the Contexts. Mahwah, NJ: Erlbaum.

Suppes, P. (1973): The semantics of children's language. American Psychologist 88, 103-114.

Tomasello, M. (1992): First Verbs: A case study of early grammatical development. Cambridge, UK: Cambridge University Press.

Vendler, Z. (1967): Verbs and times. In Z. Vendler (ed.) Linguistics in Philosophy. Ithaca, NY: Cornell University Press.

Verkuyl, H.J. (1972): On the compositional nature of the aspects. Foundations of language supplement series, 15. Dordrecht.

Weist, R., H. Wysocka, K. Witkowska-Stadnik (1984): The defective tense hypothesis: on the emergence of tense and aspect in child Polish. Journal of Child Language 11, 347-374. 